\title{
Introducing the concept of Potential Aerosol Mass (PAM)
}

\author{
E. Kang ${ }^{1}$, M. J. Root $^{1}$, D. W. Toohey ${ }^{2}$, and W. H. Brune ${ }^{1}$ \\ ${ }^{1}$ Department of Meteorology, Pennsylvania State University, University Park, PA 16802, USA \\ ${ }^{2}$ Atmospheric and Oceanic Sciences, University of Colorado, CO 80309-0311, USA
}

Received: 5 June 2007 - Published in Atmos. Chem. Phys. Discuss.: 25 June 2007

Revised: 4 October 2007 - Accepted: 29 October 2007 - Published: 20 November 2007

\begin{abstract}
Potential Aerosol Mass (PAM) can be defined as the maximum aerosol mass that the oxidation of precursor gases produces. In the measurement, all precursor gases are rapidly oxidized with extreme amounts of oxidants to low volatility compounds, resulting in the aerosol formation. Oxidation occurs in a small, simple, flow-through chamber that has a short residence time and is irradiated with ultraviolet light. The amount of the oxidants ozone $\left(\mathrm{O}_{3}\right)$, hydroxyl $(\mathrm{OH})$, and hydroperoxyl $\left(\mathrm{HO}_{2}\right)$ were measured directly and can be controlled by varying the UV light and the relative humidity. Maximum values were $40 \mathrm{ppmv}$ for $\mathrm{O}_{3} 500 \mathrm{pptv}$ for $\mathrm{OH}$, and $4 \mathrm{ppbv}$ for $\mathrm{HO}_{2}$. The oxidant amounts are 100 to 1000 times troposphere values, but the ratios $\mathrm{OH} / \mathrm{O}_{3}$ and $\mathrm{HO}_{2} / \mathrm{OH}$ are similar to troposphere values. The aerosol production mechanism and the aerosol mass yield were studied for several controlling variables, such as temperature, relative humidity, oxidant concentration, presence of nitrogen oxides $\left(\mathrm{NO}_{\mathrm{x}}\right)$, precursor gas composition and amount, and the presence of acidic seed aerosol. The measured secondary organic aerosol (SOA) yield of several natural and anthropogenic volatile organic compounds and a mixture of hydrocarbons in the PAM chamber were similar to those obtained in large, batch-style environmental chambers. This PAM method is being developed for measuring potential aerosol mass in the atmosphere, but is also useful for examining SOA processes in the laboratory and in environmental chambers.
\end{abstract}

\section{Introduction}

Secondary aerosol particles are produced by oxidizing gaseous emissions, forming low volatility compounds that either nucleate or partition on the existing aerosol particles. Secondary aerosol particles are a significant fraction of all

Correspondence to: E. Kang

(euk111@psu.edu) fine particles less than $2.5 \mu \mathrm{m}$ in diameter, called $\mathrm{PM}_{2.5}$ (IPCC, 2001). These small atmospheric aerosol particles have significant effects on human health by causing intensifying bronchial and cardiopulmonary diseases in the human lung (Krewski et al., 2000; Lall et al., 2004). They also play an important role in the global radiative balance, directly by changing light scattering and indirectly by changing cloud characteristics such as the reflectivity, size distribution, concentration, and albedo (IPCC, 2001; Seinfeld and Pandis, 1998). Understanding the origins and formation of the secondary aerosol particles is essential for understanding and predicting the impact of secondary aerosol on health and climate.

A growing body of evidence shows that organic compounds are a large fraction of most secondary aerosol particles (Murphy et al., 1998; Huebert et al., 2004; Drewnick et al., 2004b; Salcedo et al., 2006; Lanz et al., 2007). The sources of particulate organics, especially biogenic sources, are numerous and uncertain, (Kamens and Jaoui, 2001), unlike the sources for sulfate and nitrate, which are known to within an uncertainty of 20 30\% (IPCC, 2001). Quantifying the particle organic components from oxidation of precursor gases is further complicated by other factors, such as the type and concentration of the oxidants, the atmospheric humidity and temperature, the presence of nitrogen oxides $\left(\mathrm{NO}_{\mathrm{x}}\right)$, and the presence of pre-existing acidic aerosol (e.g., Seinfeld et al., 2001; Griffin et al., 1999; Presto et al., 2005b; Northcross and Jang, 2006.). These and other recent studies have begun probing the aerosol properties resulting from the oxidation of different organic precursor gases. The goal is to understand the complexities and commonalities in order to understand the mechanisms and environmental conditions that control the formation and aging of secondary organic aerosol (SOA) particles.

Inorganic secondary aerosol from sulfur dioxide $\left(\mathrm{SO}_{2}\right)$ photo-oxidation by hydroxyl $(\mathrm{OH})$, in contrast to SOA formation, is well studied experimentally and theoretically. In

Published by Copernicus Publications on behalf of the European Geosciences Union. 
particular, the binary nucleation of sulfate aerosols has been studied widely to determine the nucleation rate and the particle number concentration in ideal conditions (Jaecker-Voirol and Mirabel, 1988; Vehkamaki et al., 2002). However, while the sulfate aerosol particle is generally well understood, its interactions with nitric acid, ammonia, and organics can affect the chemical composition, mass, and volatility of the secondary aerosol particle.

Secondary organic aerosol production has been studied in the environmental chambers. In these controlled experiments, measurements of gas-phase and aerosol chemical composition, aerosol size distributions, and aerosol yield are compared to results from chemical models (for example, Kamens et al., 1999; Jang et al., 2002; Gao et al., 2004). The typical environmental chambers are large batch-style Teflon bags with volumes up to $30 \mathrm{~m}^{3}$ and residence times of several hours. These chambers are designed to simulate the timescales of SOA formation and further oxidation in the atmosphere. The large size makes this simulation possible, although wall effects remain significant and a concern (Cocker III et al., 2001). In these environmental chamber experiments, the amounts of oxidants are usually similar to those encountered in the atmosphere, with ozone being as much as several hundred ppbv and $\mathrm{OH}$ in the range of $10^{6}$ $10^{7}$ molecules $\mathrm{cm}^{-3}$. Recently a continuous laminar flow chamber with small volume of $9.5 \mathrm{~L}$ was developed that uses about 1 ppmv of ozone with a residence time of a few hours to study SOA formation (Jonsson et al., 2006). Wall effects and limited residence time remain as significant issues that may affect the fidelity of the chamber simulations to the atmosphere.

In the atmosphere, attempts have been made to measure all the SOA precursor gases, and then, using the yield data from environmental chambers, model the aerosol mass that results from the measured abundances of known aerosol precursor gases. This procedure is uncertain because not all the precursor gases may have been measured and their yields and the heterogeneous chemistry for the sampled environments may not be known. While the inorganic precursor gases $\mathrm{SO}_{2}$ and $\mathrm{NO}_{2}$ are routinely measured, the volatile organic compounds (VOCs) are much less commonly measured (Demerjian, 2000). The Photochemical Assessment Monitoring Stations in the United States of America measure some of the VOCs, but the high-molecular-weight VOCs that tend to produce secondary aerosol are scarcely measured. Thus, modeling the aerosol mass that comes from atmospheric organic emissions is difficult and uncertain.

An alternate approach is the direct and fast measurement of aerosol forming potential of air masses in the atmosphere using networks of small, inexpensive chambers. Current environmental chambers are not designed to track the fast changes of precursor gases in the atmosphere; they are too large, have a long response time, and would be difficult to replicate into a network of chambers. A new concept and measurement method are required.
We introduce a new concept: Potential Aerosol Mass (PAM). PAM can be defined as the maximum aerosol mass that the oxidation of precursor gases produces. All precursor gases are rapidly oxidized with extreme amounts of oxidants to low volatility compounds, resulting in the aerosol formation. For this approach to simulate the photo-oxidation in the atmosphere, all of the processes, including oxidation of precursor gas, nucleation, and gas and particle partitioning, should occur as they do in the atmosphere, except that instead of taking hours, the processes should be complete in a few minutes. This fast secondary aerosol formation under highly oxidizing conditions should be able to simulate the processes that occur in either the batch-style environmental chambers or, more importantly, the real atmosphere. While defining such a quantity may seem difficult, considering all the factors that affect aerosol yield, our studies indicate that it may be possible.

The term, maximum aerosol yield, was introduced by Martín-Reviejo and Wirtz (2005). Their maximum aerosol yield is calculated by the slope of the increase of aerosol mass with decrease in precursor organic species in environmental chamber experiments. Martín-Reviejo and Wirtz (2005) observed higher value for maximum aerosol yield than for overall aerosol yield, but it was due to the use of threshold of reacted precursor organic in the calculation of overall aerosol yield. Their maximum aerosol yield can be calculated for only limited SOA with mass that increases linearly with the decrease of precursor organic species. The PAM concept is completely different from the concept of maximum aerosol yield.

In this paper, we describe our initial efforts to develop the PAM concept. We provide results that indicate its feasibility and its applicability to SOA formation in the atmosphere. We describe a small, simple, flow-through chamber with a short residence time that is irradiated with ultraviolet (UV) light. The aerosol formation mechanism and the aerosol mass yield are tested for several controlling variables, such as temperature, relative humidity, oxidant concentration, precursor gas composition and amount, presence of $\mathrm{NO}_{\mathrm{x}}$, and presence of acidic seed aerosol. We compare our results for several natural and anthropogenic volatile organic compounds to others obtained in large, batch-style environmental chambers. We provide the comparison of the mass spectra of the SOA formed from m-xylene photo-oxidation in the PAM chamber and in the batch-style environmental chamber. Finally, we show the results from the first field test. We demonstrate that the PAM concept is not only applicable to the atmosphere, but is also a potent tool for studying SOA in the laboratory and in environmental chambers.

\section{Experimental method}

A prototype chamber was designed to examine the PAM concept. The basic requirements for the PAM chamber are the 
following: continuous flow with a long enough residence time that precursor gases will be fully oxidized to aerosol particles; sufficient flow to be compatible with a variety of aerosol particle sampling instruments; an air flow through the chamber that isolates particle sampling from potential wall effects; and the ability to vary the amount of UV radiation and amounts of water vapor, precursor gases, and oxidants. This prototype chamber generally meets these requirements, but is certainly not optimized.

The prototype PAM chamber is a cylinder made of Teflon FEP film $(0.5 \mathrm{~mm}$ thick) with a volume of $19 \mathrm{~L}$, a length of $60 \mathrm{~cm}$, and a diameter of $20 \mathrm{~cm}$ (Fig. 1). Two ozoneproducing UV grid lamps (BHK Inc.) are mounted one above the other on the wall of a larger, sealed housing in which the Teflon chamber is suspended. Each of these lamps is $15 \mathrm{~cm} \times 15 \mathrm{~cm}$ and produces mainly $185 \mathrm{~nm}$ and $254 \mathrm{~nm}$ light. The volume inside the housing surrounding the Teflon chamber is purged with $\mathrm{N}_{2}$ to prevent ozone formation outside of the chamber and to purge away any out-gassing from the Teflon chamber and the inside of the housing. Aerosol particles, gases, pressure, and temperature are sampled in the center at the bottom of the PAM chamber.

The sample air was continuously added to the chamber and released out through a large exhaust hose at the bottom. The chamber remained at ambient pressure. The volumetric air flow could be varied and was typically 5 to $20 \mathrm{~L} \mathrm{~min}^{-1}$. At these flow rates, the air flow was calculated to be laminar with a Reynolds number less than 500. Two different methods were tried to bring the flow into the chamber: introducing the flow through a system of perforated tubes at the top of the chamber in an effort to spread the flow across the chamber area, and introducing the air flow through a $1 \mathrm{~cm} \mathrm{di-}$ ameter tube that protrudes a few centimeters into the chamber on its cylindrical axis. The results described in this feasibility study appear to be independent of the method of introducing the air into the chamber.

We define the term, exposure time, to be the average time that the sample air is exposed to the oxidants in the chamber. In the continuous flow chamber, the amount of precursor gas that is oxidized is determined by the oxidant concentration and the exposure time. The exposure time of the PAM chamber was determined by monitoring how fast $\mathrm{SO}_{2}$ was changed from an initial value to a lower value after UV lights were turned on. At a flow rate of $5 \mathrm{~L} \mathrm{~min}^{-1}$, the exposure time was $240 \pm 36 \mathrm{~s}$ and at $10 \mathrm{~L} \mathrm{~min}^{-1}$ was $180 \pm 27 \mathrm{~s}$. That the exposure times are not inversely proportional to the flow rates suggests that the air does not flow through the chamber with a uniform velocity across the chamber cross section.

The purified dry air comes from room air that is compressed and then passed through a zero air generator (ZAG75 Labgas Inc.) and a series of filters: Drierite, activated charcoal, hopcalite, and HEPA filter pack. The purified dry air was humidified by passing it through a glass bubbler containing deionized water. The relative humidity was controlled by adjusting the fraction of the total air flow that

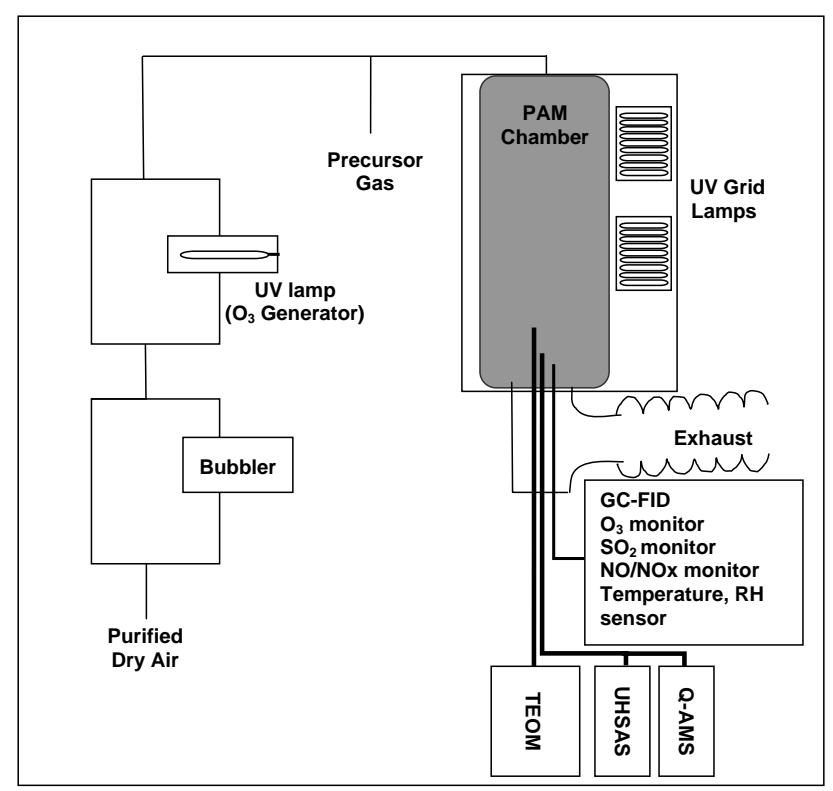

Fig. 1. Schematic diagram of the PAM chamber setup.

passed through the bubbler. The total flow rate of the purified air was controlled by mass flow controllers (1179A, 1479A, MKS Inc.).

Other gases were added to the chamber by combining mixtures of these gases to the purified air upstream of the PAM chamber. Commercially prepared mixtures were used for $\mathrm{SO}_{2}$ (10 ppmv, Scott Specialty Gases) and for NO (10 ppmv, Matheson-Trigas), both in ultra pure $\mathrm{N}_{2}$ (99.999\% pure, $<0.5 \mathrm{ppm}$ THC, GTS). The flow rates of these mixtures and others were controlled by flow controllers (MKS Inc.) that were calibrated against a DryCal flow calibrator (BIOS).

For this feasibility study, nine hydrocarbons were used: three monoterpenes ( $\alpha$-pinene, $\beta$-pinene, $\Delta^{3}$-carene), and six anthropogenic hydrocarbons (cyclohexene, m-xylene, $\mathrm{p}$ xylene, 1,3,5-trimethylbenzene (1,3,5-TMB), toluene, and ethylbenzene). The stated purities of parent hydrocarbons are as follows: $\alpha$-pinene (Fluka, 99.0\%), $\beta$-pinene (Fluka, 99.0\%), $\Delta^{3}$-carene (Fluka, 98.5\%), cyclohexene (Fluka, 99.7\%), m-xylene (Fluka, 99.5\%), p-xylene (Fluka, 99.5\%), 1,3,5-trimethylbenzene (1,3,5-TMB), (Aldrich, $1000 \mathrm{mg}$ of ampule), toluene (Fluka, 99.9\%), and ethylbenzene (Fluka, $99.5 \%)$. The hydrocarbon gas mixtures were prepared in ultra pure $\mathrm{N}_{2}(99.999 \%$ pure, $<0.5 \mathrm{ppm}$ THC, GTS) gas in the laboratory. To make a mixture, a hydrocarbon was added to a $6 \mathrm{~L}$ evacuated glass bulb and the pressure, $P_{H C}$, was measured (Baratron 390 HA, MKS Inc.). The bulb was then filled to a higher pressure with $\mathrm{N}_{2}$, creating a mixture with a mixing ratio given by the following equation:

Mixing $\cdot$ ratio $\cdot$ of $\cdot \mathrm{a} \cdot \operatorname{mixture}(\mathrm{ppmv})=\frac{P_{H C}-P_{0}}{P_{\text {Total }}-P_{0}} \times 10^{6}(1)$ where $P_{H C}$ is the hydrocarbon partial pressure, $P_{0}$ is 

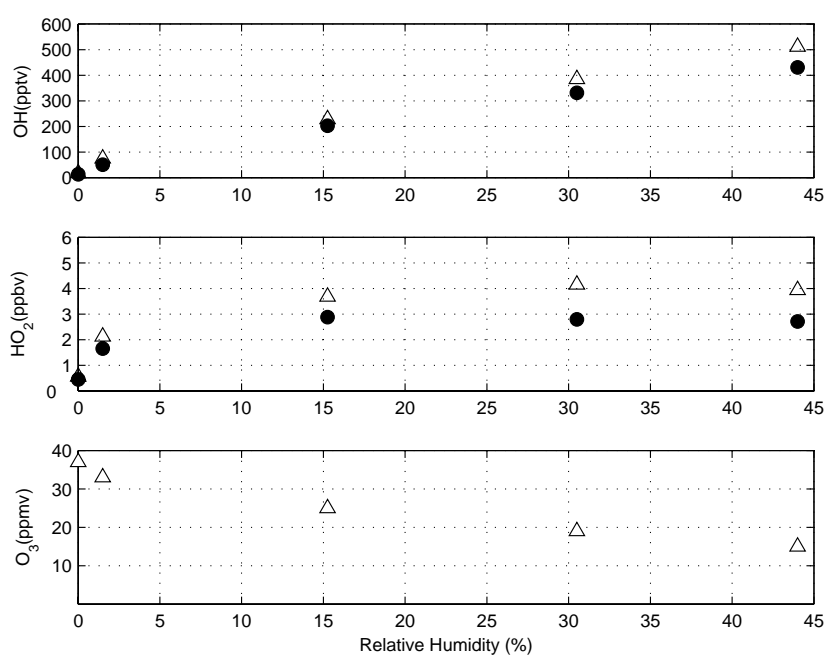

Fig. 2. $\mathrm{OH}$ and $\mathrm{HO}_{2}$, measured directly by GTHOS, and $\mathrm{O}_{3}$ in the PAM chamber as a function of relative humidity. Measurements were performed with one (filled circles) or two (open triangles) grid mercury lamps. This $\mathrm{O}_{3}$ measurement is only with two grid mercury lamps. $\mathrm{O}_{3}$ and $\mathrm{OH}$ were linearly changed with relative humidity while $\mathrm{HO}_{2}$ were not.

the minimum pressure achieved in evacuation (typically $<0.5 \mathrm{hPa}$ ), and $P_{\text {Total }}$ is the final pressure of the mixture.

The reactive gases $\mathrm{O}_{3}, \mathrm{OH}$, and $\mathrm{HO}_{2}$ were generated directly in the PAM chamber. Irradiating humid, purified air inside of the chamber with $185 \mathrm{~nm}$ UV light produced $\mathrm{OH}$ and $\mathrm{HO}_{2}$ from $\mathrm{H}_{2} \mathrm{O}$ and $\mathrm{O}_{3}$ from $\mathrm{O}_{2}$. For the studies of dark reactions with ozone, humid or dry purified air was passed through an external $\mathrm{O}_{3}$ generator (AnaLamp low pressure Hg lamp, BHK Inc.) first and then added into the purified air before entering the chamber. $\mathrm{OH}$ and $\mathrm{HO}_{2}$ were also generated in the external $\mathrm{O}_{3}$ generator, but essentially all $\mathrm{OH}$ and $\mathrm{HO}_{2}$ were reacted away before they reached to the chamber. Different $\mathrm{O}_{3}, \mathrm{OH}$, and $\mathrm{HO}_{2}$ mixing ratios were generated by varying the power supplied to the UV lamps, using one or both UV lamps, and varying the humidity. The production of reactive gases could be rapidly terminated by turning off the UV lamps.

Both gases and aerosol particles were sampled through inlets near the center of the lower end of the cylindrical PAM chamber (Fig. 1). Gaseous sample inlets were placed $5 \mathrm{~cm}$ above the bottom of the chamber. $\mathrm{O}_{3}, \mathrm{SO}_{2}$, and $\mathrm{NO} / \mathrm{NO}_{\mathrm{x}}$ in the chamber were continuously monitored by $\mathrm{O}_{3}$ monitor (model 8810 ozone analyzer, Monitor Labs Inc.), $\mathrm{SO}_{2}$ monitor (43i-TLE $\mathrm{SO}_{2}$ analyzer, Thermo Electron Corp.), and $\mathrm{NO} / \mathrm{NO}_{\mathrm{x}}$ monitor $\left(42 \mathrm{C}\right.$ Trace level $\mathrm{NO}-\mathrm{NO}_{2}-$ $\mathrm{NO}_{\mathrm{y}}$ analyzer, Thermo Environmental Instruments). Initial and final hydrocarbon concentrations were measured by Gas Chromatography-Flame Ionization Detector (8610 C, SRI) before and after the UV light was turned on. Humidity and temperature is continuously monitored by a humidity and temperature sensor (HUMICAP HMP 45A/D, Vaisala).

Two aerosol sample inlets made of stainless steel and copper tubing were placed $12 \mathrm{~cm}$ above the bottom of the chamber. Aerosol mass was mainly detected with a real-time aerosol mass measurement instrument, Tapered Element Oscillating Microbalance (TEOM 1400A, R\&P Co.). One other inlet was designed to connect additional aerosol measurement instruments such as Quadruple-Aerosol Mass Spectrometer (Q-AMS) or Ultra High Sensitivity Aerosol Spectrometer (UHSAS). The raw frequency of the TEOM mass transducer was recorded every $10 \mathrm{~s}$ and aerosol mass was calculated and averaged for $2 \mathrm{~min}$ based on the equation:

$\frac{\Delta M_{\text {filter }}}{\Delta t}=K_{0}\left(\frac{1}{f_{i+1}^{2}}-\frac{1}{f_{i}^{2}}\right)$,
$M C\left(\mu g / m^{3}\right)=\frac{\Delta M_{\text {filter }}}{\Delta t} \times \frac{1}{\text { flowrate }(1 / \mathrm{min})}$

where $\Delta M_{\text {filter }}$ is the collected particle mass on the TEOM filter at a given time, $K_{0}$ is a calibration constant of the mass transducer, $f$ is frequency, $t$ is time, $M C$ is particle mass concentration, and flowrate is a sample flow rate through the TEOM. The mass concentration calculated by the raw frequency without the manufacturer's smoothing procedure enabled us to track rapid mass changes in the PAM chamber. The aerosol mass was obtained from the difference between produced aerosol mass and the background mass, which was the aerosol mass detected in purified air.

The TEOM temperature was set to $30^{\circ} \mathrm{C}$ to reduce the evaporation artifact of semi-volatile organic aerosol (TEOM $1400 \mathrm{~A}$ monitor, Technical note 4) instead of $50^{\circ} \mathrm{C}$. The TEOM temperature setting of $30^{\circ} \mathrm{C}$ can result in increased noise due to humidity changes, but the additional noise was less than the acceptable uncertainty, $5 \mu \mathrm{g} \mathrm{m}^{-3}$ for a 10 -min average. The concern is that semi-volatile organics may be lost from the TEOM (Schwab et al., 2004; Long et al., 2005; Schwab et al., 2006; Wilson et al., 2006), even when operated at $30^{\circ} \mathrm{C}$. If significant semi-volatile mass were being lost on the TEOM in the PAM measurements, then a large negative mass signal calculated by Eq. (2) would be observed after the UV lights were turned off. However, a negative mass of only at most a few percent of the measured mass was sometimes observed in the experiments or the preliminary field study. Furthermore, for experiments in which the PAM chamber was sampled with both the TEOM and an Aerosol Mass Spectrometer (AMS), the two instruments measured the same mass to within $10 \%$. Thus, for these studies, the TEOM does not appear to be losing a significant amount of semi-volatile organic mass.

A unique feature of this PAM feasibility study is the direct quantification of $\mathrm{OH}$ and $\mathrm{HO}_{2}$ in the $\mathrm{PAM}$ chamber for different conditions. The $\mathrm{OH}$ and $\mathrm{HO}_{2}$ mixing ratios were measured separately by the Ground-based Tropospheric Hydrogen Oxides Sensor (GTHOS) (Root, 2007; Faloona et al., 2004). The TEOM inlet was replaced with the GTHOS inlet, which was at the same height in the PAM chamber that 
the TEOM inlet was. $\mathrm{OH}$ and $\mathrm{HO}_{2}$ mixing ratios were measured for the range of relative humidity used in the feasibility studies.

The behavior of $\mathrm{O}_{3}, \mathrm{OH}$, and $\mathrm{HO}_{2}$ are quite different as a function of relative humidity (Fig. 2). Ozone decreases about a factor of 2 with increasing relative humidity, unlike $\mathrm{OH}$ which increases over a factor of 10 . The slight decrease in $\mathrm{O}_{3}$ at higher humidity is due to absorption of UV by the increased water vapor, and therefore the reduction of UV in the chamber, to the reactions with $\mathrm{OH}$ and $\mathrm{HO}_{2}$, and to the photolysis of ozone and reaction with water vapor that results in the formation of $\mathrm{OH}$. Ozone could be varied from 0 to 40 ppmv. OH also depends on UV, but is roughly linearly dependent on water vapor. With the UV lamps on, $\mathrm{OH}$ could be generated over a wide range of mixing ratios, from $\sim 7 \mathrm{pptv}$ when $\mathrm{RH}$ was $\sim 0 \%$ to 500 pptv when $\mathrm{RH}$ was $\sim 45 \%$. $\mathrm{HO}_{2}$ showed quite different behavior, changing non-linearly from 100 pptv when $\mathrm{RH}$ was $\sim 0 \%$ to $\sim 4.0 \mathrm{ppbv}$ when $\mathrm{RH}$ was $15 \%$ or greater.

This behavior of $\mathrm{HO}_{2}$ and $\mathrm{OH}$ can be understood as follows. The concentrations of $\mathrm{OH}$ and $\mathrm{HO}_{2}$ are so high that the lifetimes of $\mathrm{OH}$ and $\mathrm{HO}_{2}$ are very short, much less than a second. The major loss of $\mathrm{HO}_{2}$ is the reaction $\mathrm{HO}_{2}+\mathrm{HO}_{2} \rightarrow \mathrm{HOOH}+\mathrm{O}_{2}$, and to a lesser extent the reaction $\mathrm{HO}_{2}+\mathrm{OH} \rightarrow \mathrm{H}_{2} \mathrm{O}+\mathrm{O}_{2} . \mathrm{HO}_{2}$ is at least 10 times larger than $\mathrm{OH}$, so that $\mathrm{HO}_{\mathrm{x}}$, the sum of $\mathrm{OH}+\mathrm{HO}_{2}$, is essentially equal to $\mathrm{HO}_{2}$. Because the $\mathrm{HO}_{\mathrm{x}}$ loss is quadratic in $\mathrm{HO}_{\mathrm{x}}$, the $\mathrm{HO}_{\mathrm{x}}$ concentration is equal to the square root of the $\mathrm{HO}_{\mathrm{x}}$ production:

$$
\mathrm{HO}_{2}=\sqrt{\frac{P_{\mathrm{HO}_{\mathrm{x}}}}{k_{\mathrm{HO}_{2}+\mathrm{HO}_{2}}}}
$$

From the Eq. (3), an estimate of the $\mathrm{HO}_{2}$ production rate is $3 \times 10^{9}$ molecules $\mathrm{cm}^{-3} \mathrm{~s}^{-1}$. On the other hand, the main loss for $\mathrm{OH}$ is reaction with $\mathrm{HO}_{2}$, which is essentially constant above an $\mathrm{RH}$ of $\sim 15 \%$, while $\mathrm{OH}$ production continues to increase with increasing relative humidity. As a result, the $\mathrm{OH}$ mixing ratio continues to increase proportionally with increased $\mathrm{OH}$ production since the $\mathrm{OH}$ loss is fixed.

The ratios of $\mathrm{O}_{3}$ to $\mathrm{OH}$ to $\mathrm{HO}_{2}$ are similar to those encountered during midday in the lower atmosphere. Assuming typical atmospheric values, 50 to $100 \mathrm{ppbv}$ for $\mathrm{O}_{3}, 20$ to $80 \mathrm{pptv}$ for $\mathrm{HO}_{2}$, and 0.2 to $0.5 \mathrm{pptv}$ for $\mathrm{OH}$, typical $\mathrm{O}_{3} / \mathrm{OH}$ ratios are $1 \times 10^{5}$ to $3 \times 10^{5}$ and typical $\mathrm{HO}_{2} / \mathrm{OH}$ ratios are 10 to 100 . These ratios are similar to the ratios in the PAM chamber: $2 \times 10^{5}$ for $\mathrm{O}_{3} / \mathrm{OH}$ and $\sim 15$ for $\mathrm{HO}_{2} / \mathrm{OH}$. Thus, in terms of major oxidants, the PAM chamber can simulate atmospheric oxidation processes, but at greatly accelerated rates.

The $\mathrm{OH}$ and $\mathrm{HO}_{2}$ mixing ratios were measured at the bottom of the PAM chamber. The $\mathrm{OH}$ mixing ratio derived from the change in $\mathrm{SO}_{2}$ observed with and without the UV lights on agrees to well within uncertainties with the $\mathrm{OH}$ measured directly by GTHOS (Root, 2007). This agreement between direct and indirect $\mathrm{OH}$ measurements suggests that the $\mathrm{OH}$ distribution in the chamber is fairly uniform. Furthermore, the directly measured $\mathrm{OH}$ and $\mathrm{HO}_{2}$ mixing ratios allow the $\mathrm{OH}$ and $\mathrm{HO}_{2}$ mixing ratios to be estimated from knowledge of solely the UV light intensity and the relative humidity. Better control on these parameters will be built into the next version of the PAM measurement.

\section{Results and discussion}

3.1 Feasibility test of the PAM concept: $\mathrm{SO}_{2}$ conversion to sulfate aerosol

The quantitative conversion of $\mathrm{SO}_{2}$ to inorganic sulfate aerosol was studied to demonstrate the PAM concept, even though the greatest value for PAM is improving the understanding of secondary organic aerosol. The oxidation pathways, nucleation process, sulfate mass per amount of $\mathrm{SO}_{2}$, and unity yield are all well known:

$$
\begin{aligned}
& \mathrm{SO}_{2}(g)+\mathrm{OH} \cdot \stackrel{\text { oxidation }}{\longrightarrow} \mathrm{H}_{2} \mathrm{SO}_{4}(g) \\
& \mathrm{H}_{2} \mathrm{SO}_{4}(g)+\mathrm{H}_{2} \mathrm{O}(g) \stackrel{\text { nucleation }}{\longrightarrow} \text { sulfate } \cdot \text { aerosol }
\end{aligned}
$$

where $\mathrm{k}_{\mathrm{OH}+\mathrm{SO}_{2}}=9.0 \times 10^{-13}$ molecule ${ }^{-1} \mathrm{~cm}^{3} \mathrm{~s}^{-1}$ at $298 \mathrm{~K}$ for the initial reaction of $\mathrm{SO}_{2}$ with $\mathrm{OH}$. Thus, simultaneous measurements of $\mathrm{SO}_{2}$ and sulfate aerosol mass test both the rapid oxidation and nucleation of aerosol particles and the possible loss of sulfate aerosol particles to the walls.

The theoretical value of the maximum sulfate aerosol produced in the PAM chamber is calculated by the equation:

The $\cdot$ calculated $\cdot$ conversion $\cdot$ ratio

$$
\begin{aligned}
& =\chi\left(\mathrm{SO}_{2}(1 \cdot \mathrm{ppbv})\right) \times \frac{\text { mass } \cdot \text { of sulfur }}{\mathrm{SO}_{2} \text { volume }} \\
& \times \frac{\mathrm{H}_{2} \mathrm{SO}_{4} \text { mass }}{\text { mass. of } \cdot \text { sulfur }} \times \text { growth.factor }
\end{aligned}
$$

The growth factor is given by the equation:

$$
\text { growth } \cdot \text { factor(f) }=\frac{m_{\mathrm{H}_{2} \mathrm{SO}_{4}}+m_{\mathrm{H}_{2} 0}}{m_{\mathrm{H}_{2} \mathrm{SO}_{4}}}
$$

The calculation assumes that $\mathrm{OH}$ is in great excess in the chamber and that all of the oxidized $\mathrm{SO}_{2}$ becomes sulfate aerosol. One ppbv of $\mathrm{SO}_{2}$ produces $3.95 \mu \mathrm{g} \mathrm{m}^{-3}$ of $\mathrm{H}_{2} \mathrm{SO}_{4}$. A complication is the water uptake on the sulfate aerosol particles, which makes the aerosol particle mass dependent on relative humidity $(\mathrm{RH})$. As a result, the conversion ratio from $\mathrm{SO}_{2}$ to sulfate aerosol particle mass depends on a humiditydependent growth factor. The growth factor as a function of relative humidity is calculated by the theoretical model of Jaecker-Voirol et al. (1990). For example, at a relative humidity of $28 \%$ and a TEOM temperature of $30^{\circ} \mathrm{C}$, total conversion of $1 \mathrm{ppbv}$ of $\mathrm{SO}_{2}$ produces $5.8 \mu \mathrm{g} \mathrm{m}^{-3}$ of sulfate aerosol. The water uptake of the sulfate aerosol particles rapidly adjusts to equilibrium with the relative humidity, so that the relative humidity that is important in determining the aerosol particle mass is the relative humidity at the TEOM mass transducer. 
(a)

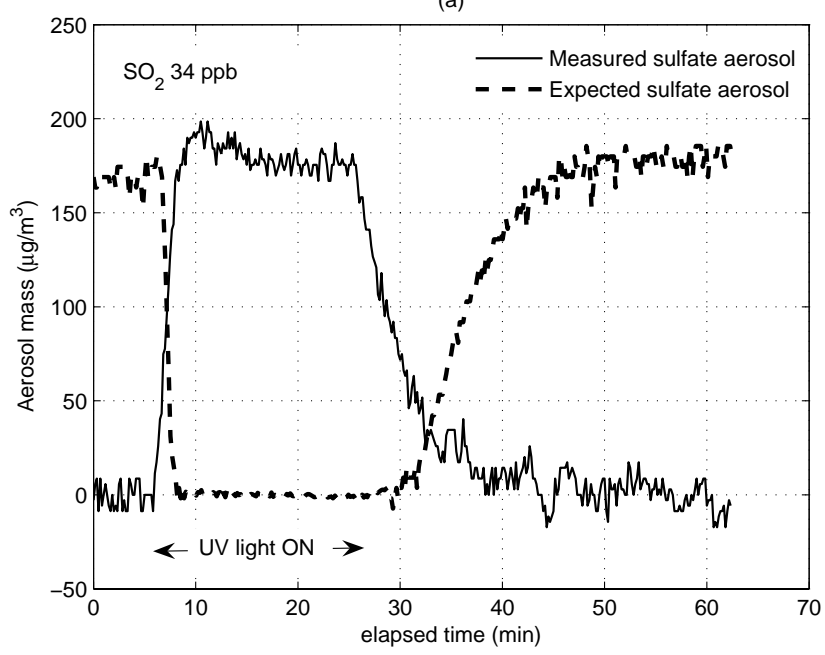

(b)

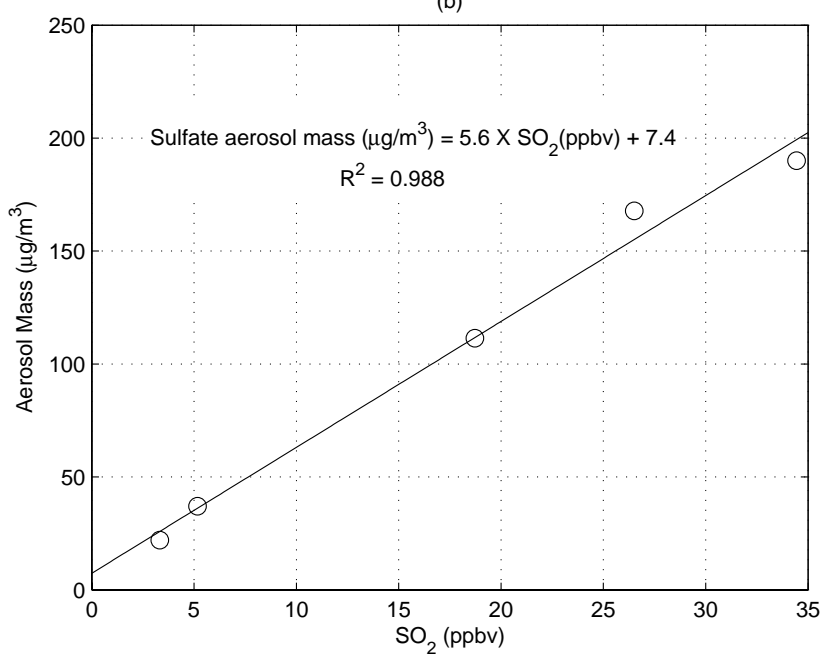

Fig. 3. (a) Measured and expected sulfate aerosol in the PAM chamber with $34 \mathrm{ppb}$ of $\mathrm{SO}_{2}$. The expected sulfate aerosol was obtained by the measured $\mathrm{SO}_{2}$ mixing ratio multiplied by the calculated conversion ratio $5.8 \mu \mathrm{g} \mathrm{m}^{-3}$ ( $\left.\mathrm{ppbv} \mathrm{SO}_{2}\right)^{-1}$ for a TEOM temperature of $30^{\circ} \mathrm{C}$ and a relative humidity of $28 \%$. (b) Measured sulfate aerosol mass versus $\mathrm{SO}_{2}$. The least squares slope of $5.6 \mu \mathrm{g} \mathrm{m}^{-3}$ (ppbv $\left.\mathrm{SO}_{2}\right)^{-1}$ is well within measurement uncertainty of the calculated slope of $5.8 \mu \mathrm{g} \mathrm{m}^{-3}\left(\mathrm{ppbv} \mathrm{SO}_{2}\right)^{-1}$.

A range of $\mathrm{SO}_{2}$ mixing ratios from $3 \mathrm{ppbv}$ to $35 \mathrm{ppbv}$ were added to the air flow in the chamber. For these experiments, the air flow rate was $5 \mathrm{~L} \mathrm{~min}^{-1}$, the exposure time to the UV light was $240 \pm 36 \mathrm{~s}$, and the relative humidity was $40 \%$ in the chamber and $28 \%$ at the TEOM mass transducer (Fig. 3). Both UV grid lamps were on, producing $450 \mathrm{pptv}$ of $\mathrm{OH}$ in the chamber.

The unsmoothed TEOM mass was calculated from the raw frequency change measurements (Fig. 3). For this graph, the $\mathrm{SO}_{2}$ mixing ratios have been converted to sulfate mass using the calculated conversion ratio of $5.8 \mu \mathrm{g} \mathrm{m}^{-3}$ appropri- ate for the $28 \%$ relative humidity at the TEOM mass transducer. The aerosol mass quickly increased to the stable value simultaneously as $\mathrm{SO}_{2}$ dropped down to background levels. The aerosol mass calculated from the raw frequency indicated that sulfate aerosol formation was completed in a few minutes in the PAM chamber. The slope in Fig. $3 \mathrm{~b}$ represents the measured conversion ratio, $5.6 \mu \mathrm{g} \mathrm{m}^{-3}\left(\mathrm{ppbv} \mathrm{SO}_{2}\right)^{-1}$, which agrees to well with the expected conversion ratio of $5.8 \mu \mathrm{g} \mathrm{m}^{-3}\left(\mathrm{ppbv} \mathrm{SO}_{2}\right)^{-1}$.

The effect of TEOM temperature on sulfate aerosol was tested by changing TEOM temperature setting from $30^{\circ} \mathrm{C}$ to $50^{\circ} \mathrm{C}$. The calculated and measured conversion ratios agree well for both of $30^{\circ} \mathrm{C}$ and $50^{\circ} \mathrm{C}$. At a temperature of $50^{\circ} \mathrm{C}$ and relative humidity of $18 \%$ in the TEOM mass transducer, the measured conversion ratio was $4.69 \mu \mathrm{g} \mathrm{m}^{-3}$ (ppbv $\left.\mathrm{SO}_{2}\right)^{-1}$ and calculated conversion ratio was $4.98 \mu \mathrm{g} \mathrm{m}^{-3}$ $\left(\mathrm{ppbv} \mathrm{SO}_{2}\right)^{-1}$. Thus, the sulfate aerosol formation is not affected by the TEOM temperature. For most of our studies of inorganic and organic secondary aerosol, the TEOM mass transducer temperature was kept at $30^{\circ} \mathrm{C}$.

The wall loss of precursor gases was tested by measuring the $\mathrm{SO}_{2}$ mixing ratio in and out of the chamber. Less than $20 \%$ of $\mathrm{SO}_{2}$ was lost on entrance into the chamber and on the Teflon chamber wall. This low wall loss rate is due in part to the relatively fast continuous flow in the PAM chamber. This small wall loss for $\mathrm{SO}_{2}$ suggests that other gases can be brought through the chamber with at most a small loss, but careful tests of inlet materials and heated and unheated inlets will be needed to minimize the loss of oxygenated VOCs and semi-volatile VOCs in the inlet lines and PAM chamber.

$\mathrm{SO}_{2}$ conversion to sulfate aerosol was performed frequently to monitor the chamber's ability to reproduce the sulfate Potential Aerosol Mass (PAM) quantitatively. For four $\mathrm{SO}_{2}$ experiments, the measured conversion ratio was $92 \pm 4 \%$ of the calculated conversion ratio, well within the absolute uncertainty of $\sim 13 \%$ and $\sim 12 \%$ for the calculated conversion ratio and for the measured conversion ratio, respectively.

These experiments show that $\mathrm{SO}_{2}$ can be completely converted to sulfate aerosol particles in the few minutes of exposure time in the PAM chamber. The oxidation of $\mathrm{SO}_{2}$ by $\mathrm{OH}$ is relatively slow compared to most hydrocarbon oxidation by $\mathrm{OH}$, with $\mathrm{k}_{\mathrm{OH}+\mathrm{SO}_{2}}=9.0 \times 10^{-13}$ molecule ${ }^{-1} \mathrm{~cm}^{3} \mathrm{~s}^{-1}$. For example, $\alpha$-pinene reacts with $\mathrm{OH}$ with a reaction rate coefficient of $\mathrm{k}_{\mathrm{OH}+\alpha \text {-pinene }}=5.5 \times 10^{-11}$ molecule ${ }^{-1} \mathrm{~cm}^{3} \mathrm{~s}^{-1}$. Essentially all SOA precursor gases react at least 3 times faster with $\mathrm{OH}$ than $\mathrm{SO}_{2}$ does, so that these hydrocarbons should be completely oxidized in the PAM chamber. This conclusion is supported by GC-FID measurements of the 9 hydrocarbons that were studied. They were all depleted to below the detection limit in the PAM chamber after the UV lights were turned on. 
3.2 Feasibility tests of the PAM concept with organic gas conversion to SOA

The feasibility of the PAM concept was checked by varying several parameters that might affect the SOA mass yield. The well-studied precursor gas, $\alpha$-pinene, was chosen for most of the tests. In the series of experiments, the goal was to determine the conditions for which the PAM chamber would produce the maximum SOA yield. The SOA yield was obtained by the equation (Seinfeld et al., 2001):

SOA $\cdot$ Yield $(\mathrm{Y})=\frac{M_{o}(\text { produced } \cdot \text { organic } \cdot \text { aerosol } \cdot \text { mass })}{\Delta H C(\text { reacted } \cdot \text { hydrocarbon } \cdot \text { mass })}$

A typical procedure for these experiments was to first establish the flows of all the gases, then turn on the UV lights until the signal stabilized, and then turn off the UV lights again, as in Fig. 3a. For the $\mathrm{SO}_{2}$ experiments, the aerosol mass would quickly rise to near its peak value as the $\mathrm{SO}_{2}$ value fell and then remain there. In most secondary organic aerosol experiments with sufficient oxidants, the aerosol mass would quickly rise to a peak within a minute or so, but would then decrease to a smaller stable value.

This behavior is a transient phenomenon that is observed only in the PAM with the pure organics and a mixture of 3 organics when we turn on the UV light to initiate the oxidation. When we ran the chamber with the UV light on continuously for a stable oxidant level, and added precursor gas later, we did not observe the peak mass and the following stable mass. Interestingly, it is not observed in the atmosphere, as shown later in the paper (Fig. 12). That it is not observed in the large environmental chambers suggests that it is due to the extremely rapid initial particle formation in the PAM chamber. We cannot yet explain this behavior. However, it had no effect on the observed stable SOA properties that are discussed in this paper. We will examine this behavior and the roles that $\mathrm{OH}$ and $\mathrm{HO}_{2}$ play in more detail in another manuscript. For the feasibility study in this manuscript, we will use the SOA mass observed after stabilization in the equation for aerosol mass yield Eq. (7).

\subsubsection{SOA yield as a function of $\mathrm{O}_{3}$}

The effect of ozone on the SOA yield from $\alpha$-pinene was studied by varying the ozone mixing ratio in the chamber using purified dry air $(\mathrm{RH}<1 \%)$ (Fig. 4). The initial $\alpha$-pinene mixing ratio was $100 \mathrm{ppbv}$. Ozone was varied by changing the flow rate through an external ozone generator, changing the UV lamp intensity with a controllable power supply, and covering a fraction of the UV lamps with an aluminum cover. Ozone was produced in the range of $0.7 \mathrm{ppmv}$ to $27 \mathrm{ppmv}$. $\mathrm{OH}$ was about $7 \mathrm{pptv}$ and $\mathrm{HO}_{2}$ was 450 pptv in the dry, purified air. These $\mathrm{OH}$ and $\mathrm{HO}_{2}$ values were 10 to 50 times larger than observed in the troposphere, but ozone values were more than 100 times larger than observed in the troposphere.

The aerosol mass initially increased as ozone increased, but then reached a constant maximum stable value for ozone

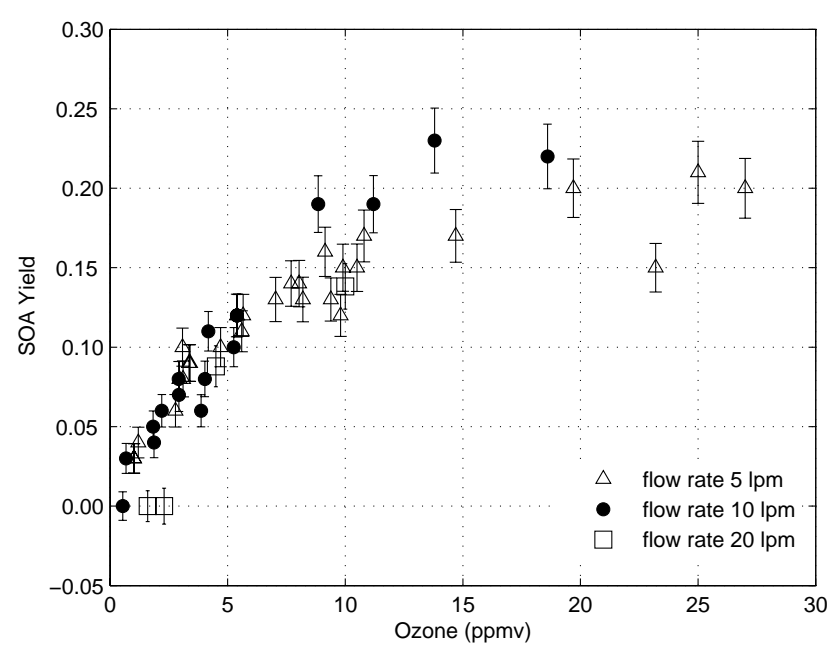

Fig. 4. The SOA yield as a function of chamber flow rate and $\mathrm{O}_{3}$ in the dry condition with $100 \mathrm{ppbv}$ of $\alpha$-pinene. The dominant oxidant in this study is ozone. Three different flow rates are used to change residence time in the chamber. Error bars show the precision $(1 \sigma)$ for SOA yields.

greater than $\sim 12$ ppmv. Thus, ozone levels greater than $\sim 12$ ppmv were sufficient to achieve maximum aerosol mass concentration. It is also important to note that higher levels of $\mathrm{O}_{3}$ do not reduce the aerosol yield, suggesting that $\mathrm{O}_{3}$ does not react significantly with the $\alpha$-pinene reaction products that influence the SOA yield. Additional ozone is not expected to reduce the SOA yield from $\alpha$-pinene because it has only one double carbon bond ( $\mathrm{Ng}$ et al., 2006). This result demonstrates that the extreme oxidation in the PAM chamber is occurring as expected for this reaction.

\subsubsection{SOA yield as a function of air flow rate in the cham- ber}

The flow rate of air through the chamber affects primarily the exposure time in the PAM chamber. In order to achieve maximum aerosol mass, the exposure time in the chamber must be sufficient to allow for the oxidation of the precursor gas, the aerosol particle nucleation, the condensation of the lowvolatility product, and any particle-phase or gas-phase reactions that occur. The higher the flow rate means the shorter the exposure time in the PAM chamber.

The SOA yield from ozonolysis of $100 \mathrm{ppbv}$ of $\alpha$-pinene in dry conditions was measured as a function of ozone for three flow rates: 5,10 , and $20 \mathrm{~L} \mathrm{~min}^{-1}$ (Fig. 4). The behavior of SOA yield as a function of $\mathrm{O}_{3}$ appears to be similar for flow rates of 5 and $10 \mathrm{~L} \mathrm{~min}^{-1}$. The SOA yield for the $20 \mathrm{~L} \mathrm{~min}^{-1}$ flow rate appears to be less than the other two, but not enough data could be obtained at higher ozone values to see if the aerosol yield leveled off at higher ozone values as it did for the slower flow rates. That the SOA yields at the $5 \mathrm{~L} \mathrm{~min}^{-1}$ and $10 \mathrm{~L} \mathrm{~min}^{-1}$ flow rates were similar indicates 


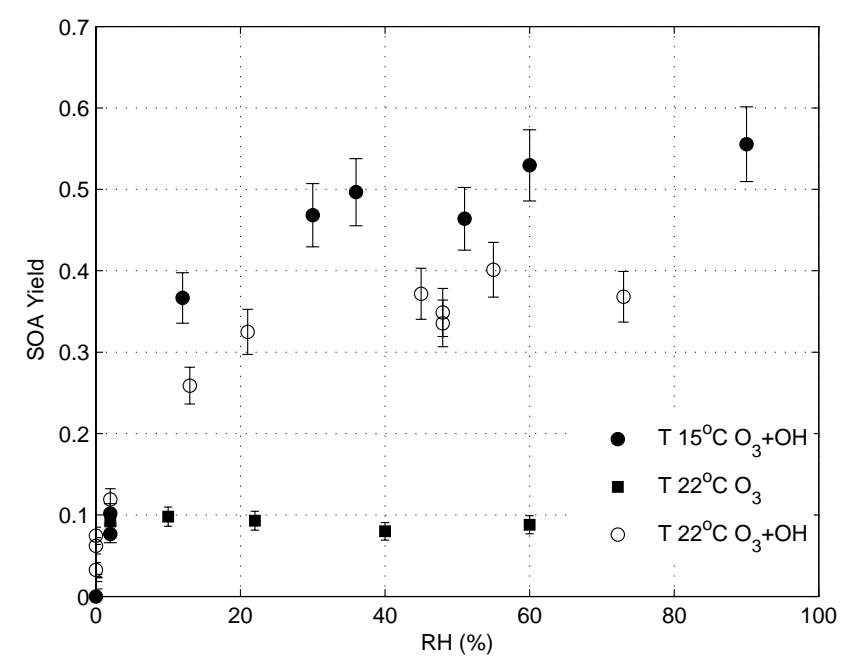

Fig. 5. SOA yield as a function of relative humidity in the UVirradiated chamber with $\mathrm{T}=15^{\circ} \mathrm{C}$ (filled circles) and $\mathrm{T}=22^{\circ} \mathrm{C}$ (open circles) and in the dark chamber (filled squares). Ozone was constant at 5 ppmv and $\alpha$-pinene was initially 100 ppbv. Error bars show the precision $(1 \sigma)$ for SOA yields.

that the PAM chamber could be smaller than its present size and still achieve maximum SOA yields.

\subsubsection{SOA yield as a function of $\mathrm{OH}$}

The SOA yield in UV irradiated chamber was about 5 times that in the dark chamber at same relative humidity and temperature (Fig. 5). This additional SOA yield likely comes from the reaction of $\mathrm{OH}$ with $\alpha$ pinene. The rate constants of $\alpha$-pinene with $\mathrm{OH}$ and with $\mathrm{O}_{3}$ are about $5.5 \times 10^{-11}$ molecule ${ }^{-1} \mathrm{~cm}^{3} \mathrm{~s}^{-1}$ and $8.2 \times 10^{-17}$ molecule ${ }^{-1} \mathrm{~cm}^{3} \mathrm{~s}^{-1}$ from $288 \mathrm{~K}$ to $295 \mathrm{~K}$ (NIST chemical kinetics database, 2000). Since $5 \mathrm{ppmv}$ of $\mathrm{O}_{3}$ and $300 \mathrm{pptv}$ of $\mathrm{OH}$ are produced when the relative humidity was $30 \%$ and one UV light was on, the value of $\mathrm{k}_{\mathrm{OH}}[\mathrm{OH}]$ was about 20 times greater than $\mathrm{k}_{3}\left[\mathrm{O}_{3}\right]$. Thus, the photo-oxidation by $\mathrm{OH}$ was the most important reaction in the humid, UV-irradiated chamber. The oxidation pathways opened up by reactions with $\mathrm{OH}$ produce additional low volatility products for the particle phase (Kamens and Jaoui, 2001). The increased SOA yield in the PAM chamber when abundant $\mathrm{OH}$ is present is consistent with these additional pathways.

The $\mathrm{OH}$ mixing ratio was changed by varying the relative humidity while holding $\mathrm{O}_{3}$ (5 ppmv) and UV light constant (Fig. 6). As OH increased, SOA yield increased but eventually leveled off for $\mathrm{OH}$ greater than $300 \mathrm{pptv}$. Thus, in this PAM chamber, $300 \mathrm{pptv}$ of $\mathrm{OH}$ was sufficient to produce the maximum SOA yield for $\alpha$-pinene.

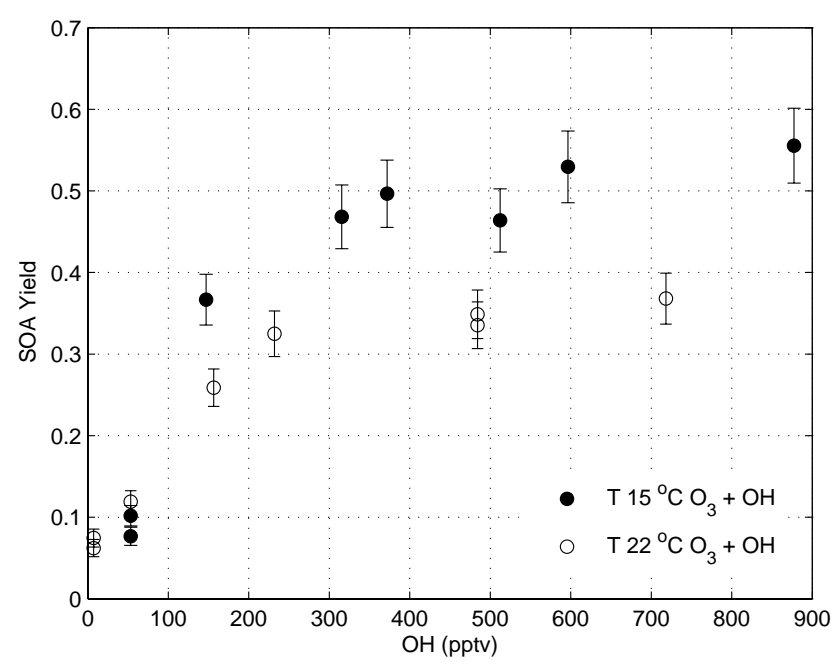

Fig. 6. SOA yield as a function of $\mathrm{OH}$ for $\mathrm{T}=15^{\circ} \mathrm{C}$ (filled circles) and $\mathrm{T}=22^{\circ} \mathrm{C}$ (open circles) in the UV-irradiated chamber for photooxidation by $\mathrm{OH}$ and $\mathrm{O}_{3}$. Ozone was constant at 5 ppmv; initial $\alpha$-pinene was 100 ppbv. Error bars show the precision $(1 \sigma)$ for SOA yields.

\subsubsection{SOA yield as a function of temperature and humidity}

Temperature and humidity can both have an effect on aerosol mass yield (see for example Seinfeld and Pankow, 2003). The effect of temperature on the SOA yield from $\alpha$-pinene was tested by measuring the SOA yield with two different temperatures in the chamber, $22^{\circ} \mathrm{C}$ and $15^{\circ} \mathrm{C} . \mathrm{O}_{3}$ was held constant at 5 ppmv while $\mathrm{OH}$ was varied by changing relative humidity. At low relative humidity (Fig. 5) and $\mathrm{OH}$ (Fig. 6), the SOA yields at $15^{\circ} \mathrm{C}$ and $22^{\circ} \mathrm{C}$ are comparable. However, the maximum stable SOA yield for $15^{\circ} \mathrm{C}$ is a factor of 1.4 greater than that at $22^{\circ} \mathrm{C}$. The increased SOA yield at the lower temperature can be explained by the decrease in the partitioning of $\alpha$-pinene products in the particle phase with increasing temperature (Pankow et.al., 2001). This temperature dependence applies to other organics as well. Therefore the definition of PAM may require that the measurement be made at a standard temperature or be made at several temperatures over a range of temperatures.

The effect of relative humidity on SOA yield was tested using oxidation primarily by ozone. The relative humidity was varied from 2 to $60 \%$ in purified air, to which ozone and $\alpha$-pinene were added before the air flowed into and through the dark chamber. (Fig. 5, filled squares). In this case, the SOA yield did not change as relative humidity was increased, indicating that the relative humidity itself is not an important factor to change SOA yield for $\alpha$-pinene ozonolysis. This result is consistent with a previous study of $\alpha$-pinene ozonolysis, in which increasing the relative humidity from 0 to $40 \%$ in the seed-free condition increased the SOA mass only $10 \%$, including the water mass in the aerosol particles (Cocker III et al., 2001). 


\subsubsection{SOA yield as a function of UV radiation}

Extremely high UV actinic flux could possibly alter the SOA yields and the gas and particle product composition (Kamens and Jaoui 2001; Presto et al., 2005a). A test for this possibility with PAM is the comparison of the SOA yields that comes from adding ozone in the dark chamber to that from making the same amount of ozone in the chamber with UV radiation. The aerosol yield is compared for four cases: dark, dry chamber (externally generated ozone added to dry air $(\mathrm{RH}<1 \%)$ in a dark chamber); UV-irradiated dry chamber (ozone generated by UV radiation in the chamber in dry air ( $\mathrm{RH}<1 \%$ ), in order to minimize $\mathrm{OH}$ and $\mathrm{HO}_{2}$ production); dark, humid chamber (with externally generated ozone added to air with $\mathrm{RH}=12 \%$ in a dark chamber); and UV-irradiated humid chamber (with ozone generated by UV radiation in the chamber in air with $\mathrm{RH}=12 \%$ ). In all cases but the last case, $\mathrm{OH}$ was less than 15 pptv, about $10^{-6}$ times less than $\mathrm{O}_{3}$, so that $\mathrm{O}_{3}$ reactions with $\alpha$-pinene dominate. In the case of the UV-irradiated humid chamber, the $\mathrm{OH} / \mathrm{O}_{3}$ ratio was at least $9 \times 10^{-6}$ when $\mathrm{O}_{3}$ was 15 ppmv and $\mathrm{OH}$ was 150 pptv; the $\mathrm{OH}$ reactions with $\alpha$-pinene were much more significant.

The SOA yield for the dark, dry chamber and UVirradiated, dry chamber are the same to within uncertainties for as much as 6 ppmv of ozone (Fig. 7). The external ozone generator could not produce more than 6 ppmv of ozone, so that above 6 ppmv, only yields from the UV irradiated chamber cases are shown. The yield for the case of the dark, humid chamber is slightly less than the dry chamber cases. This effect needs further investigation. On the other hand, the yield for the case of the UV-irradiated humid chamber is significantly greater than all the other cases, indicating the importance of $\mathrm{OH}$ in oxidizing $\alpha$-pinene to SOA.

This agreement between the SOA yield in the dark, dry chamber and in the UV-irradiated dry chamber is inconsistent with the observations of Presto et al. (2005a). They observed a 20 to $40 \%$ reduction in SOA yield between the case in which the chamber was UV-irradiated and the case in which ozone was added to a dark chamber. In both cases, they used cleaned air with $\mathrm{RH}<10 \%$ and added up to $600 \mathrm{ppbv}$ of ozone into the chamber. In order to remove $\mathrm{OH}$ in the chamber, they added 2-butanol and calculated that as much as $90 \%$ of the $\mathrm{OH}$ was removed.

The difference between the two observations could be explained by the existence of 10 to $15 \mathrm{pptv}$ of $\mathrm{OH}$ in the UVirradiated, dry PAM chamber. This amount of $\mathrm{OH}$ was produced from the photolysis of a trace amount of $\mathrm{H}_{2} \mathrm{O}$ that was in the dry air that entered the PAM chamber. This amount of $\mathrm{OH}$ will react with $\alpha$-pinene about as fast as $6 \mathrm{ppmv}$ of $\mathrm{O}_{3}$. It is possible that a loss of SOA caused by UV radiation is balanced by an increase in SOA yield from this $\mathrm{OH}$ produced by UV in the chamber. This balance seems unlikely but will be tested by varying the humidity and thus $\mathrm{OH}$ for a fixed UV flux, to fix $\mathrm{OH}$ by varying humidity and UV simultaneously and by adding a window in front of the UV lamps to

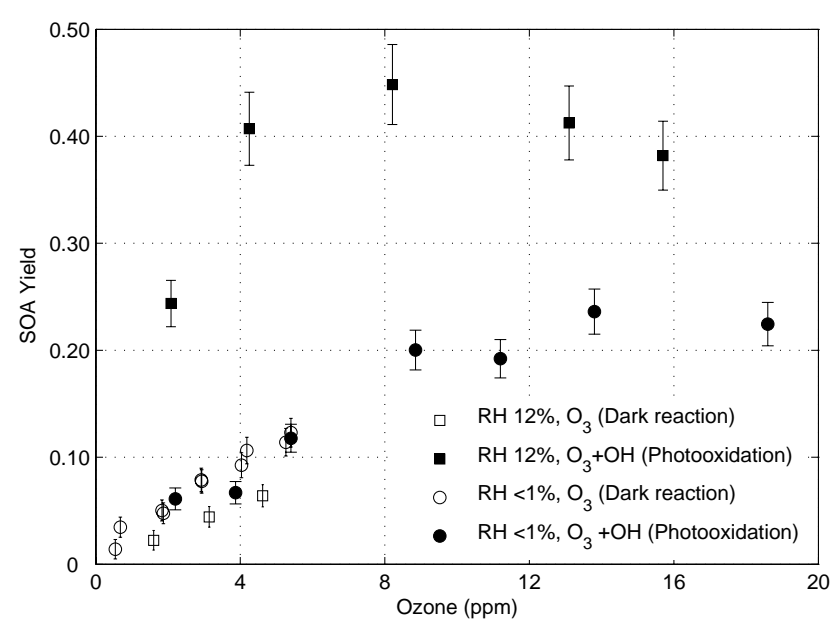

Fig. 7. SOA yield as a function of ozone for four chamber conditions: dark, humid chamber (open squares); and UV-irradiated humid chamber (filled squares), dark, dry chamber (open circles); UV-irradiated, dry chamber (filled circles). Initial $\alpha$-pinene was 100 ppbv. Error bars show the precision $(1 \sigma)$ for SOA yields.

block the $\mathrm{OH}$-producing $185 \mathrm{~nm}$ radiation while passing the $254 \mathrm{~nm}$ radiation into the PAM chamber.

The difference between our result and that of Presto et al. (2005a) may also be due to the difference between our UV lamps, which have strong emissions at $185 \mathrm{~nm}$ and $254 \mathrm{~nm}$, and their black lights, which have a broad spectral emission between $350 \mathrm{~nm}$ and $400 \mathrm{~nm}$ and no emissions at $185 \mathrm{~nm}$ and $254 \mathrm{~nm}$. While it might be thought that the more energetic emissions at $185 \mathrm{~nm}$ and $254 \mathrm{~nm}$ would be more effective than the $350-400 \mathrm{~nm}$ emissions from the black lights, we do not know the absorption cross sections for the photoreactions that would reduce the SOA yield.

3.2.6 SOA yield as a function of acidic seed aerosol particles

Acidic seed aerosol particles have been shown to increase the aerosol yield under some circumstances (Jang et al., 2002; Northcross and Jang, 2006). The effect of acidic seed was tested with the addition of sulfate aerosol in a humid UVirradiated chamber. $\mathrm{SO}_{2}$ was added to the chamber; the acidic seed aerosol particles were formed by photo-oxidation of $\mathrm{SO}_{2}$ initiated by reaction with $\mathrm{OH}$. Once the measured sulfate aerosol mass was stabilized, $\alpha$-pinene was added to the chamber. The SOA that resulted from the oxidation of the $\alpha$-pinene by $\mathrm{OH}$ and $\mathrm{O}_{3}$ was determined by subtracting the aerosol mass obtained with just $\mathrm{SO}_{2}$ added to the chamber from the aerosol mass obtained with both $\alpha$-pinene and $\mathrm{SO}_{2}$ in the chamber.

For all values of $\alpha$-pinene from $50 \mathrm{ppbv}$ to $270 \mathrm{ppbv}$, the SOA yield is up a factor of 1.4 higher in the presence of the acidic seed aerosol than it is in the no-seed added experiments (Fig. 8). For this study, 5 ppbv of $\mathrm{SO}_{2}$ was added, 
Table 1. SOA formation from photooxidation.

\begin{tabular}{|c|c|c|c|c|c|c|c|}
\hline VOC & $\begin{array}{l}\text { Temp } \\
(\mathrm{K})\end{array}$ & $\begin{array}{l}\mathrm{RH} \\
(\%)\end{array}$ & $\begin{array}{l}\Delta \mathrm{HC} \\
(\mathrm{ppb})\end{array}$ & $\begin{array}{l}\mathrm{NO}_{\mathrm{x}} \\
(\mathrm{ppb})\end{array}$ & $\begin{array}{l}{\mathrm{HC} / \mathrm{NO}_{\mathrm{x}}} \\
(\mathrm{ppbC} / \mathrm{ppb})\end{array}$ & SOA Yield & Reference Yield \\
\hline$\alpha$-pinene & 298 & $<2$ & $100 \pm 12$ & $\mathrm{~N} / \mathrm{M}$ & $\mathrm{N} / \mathrm{M}^{1}$ & $0.20 \pm 0.03^{2}$ & $0.23^{3}\left(\mathrm{O}, 91\right.$, Presto et al., $\left.2005 \mathrm{~b}^{4}\right)$ \\
\hline$\left(\mathrm{C}_{10} \mathrm{H}_{12}\right)$ & 298 & $14-24$ & $100 \pm 12$ & $\mathrm{~N} / \mathrm{M}$ & N/M & $0.40 \pm 0.10$ & $0.32(\mathrm{P}, 109$, Lee et al., 2006) \\
\hline$\beta$-pinene & 298 & 42 & $156 \pm 19$ & $<3$ & $>500$ & $0.49 \pm 0.06$ & 0.27 (P, 97, Griffin et al., 1999) \\
\hline$\left(\mathrm{C}_{10} \mathrm{H}_{12}\right)$ & 298 & 42 & $156 \pm 19$ & 43 & 36 & $0.48 \pm 0.06$ & $\begin{array}{l}0.31 \text { (P, 170, Lee et al., 2006) } \\
0.32 \text { (P, 170, Varutbangkul et al., 2006) }\end{array}$ \\
\hline$\Delta^{3}$-carene & 297 & 48 & $161 \pm 18$ & $<3$ & $>500$ & $0.07 \pm 0.01$ & 0.18 (P, 105, Griffin et al., 1999) \\
\hline$\left(\mathrm{C}_{10} \mathrm{H}_{16}\right)$ & 297 & 48 & $161 \pm 18$ & 89 & 18 & $0.13 \pm 0.02$ & 0.38 (P, 109, Lee et al., 2006) \\
\hline $\begin{array}{l}\text { cyclohexene } \\
\left(\mathrm{C}_{6} \mathrm{H}_{10}\right)\end{array}$ & 298 & 40 & $266 \pm 18$ & $\mathrm{~N} / \mathrm{M}$ & $\mathrm{N} / \mathrm{M}$ & $0.19 \pm 0.01$ & $\begin{array}{l}0.12 \text { (O, 151, Varutbangkul et al., 2006) } \\
0.14 \text { (O, 240, Keywood et al., 2004) }\end{array}$ \\
\hline $\begin{array}{l}\text { m-xylene } \\
\left(\mathrm{C}_{8} \mathrm{H}_{10}\right)\end{array}$ & 298 & 55 & $324 \pm 28$ & $<3$ & $>500$ & $0.10 \pm 0.01$ & $\begin{array}{l}0.13 \text { (P, 322, Cocker III et al., 2001) } \\
0.06 \text { (P, 355, Odum et al., 1997) } \\
0.08 \text { (P,311, Song et al., 2005) } \\
0.39^{5} \text { (P, 60, Ng et al., 2007) }\end{array}$ \\
\hline p-xylene & 297 & 40 & $170 \pm 11$ & $<3$ & $>500$ & $0.05 \pm 0.01$ & 0.03 (P, 199, Odum et al., 1997) \\
\hline$\left(\mathrm{C}_{8} \mathrm{H}_{10}\right)$ & 297 & 40 & $170 \pm 11$ & 107 & 13 & $0.07 \pm 0.01$ & \\
\hline 1,3,5-TMB & 298 & $<2$ & $682 \pm 31$ & $<3$ & $>500$ & $0.06 \pm 0.01$ & 0.07 (P, 543, Cocker III et al., 2001) \\
\hline$\left(\mathrm{C}_{9} \mathrm{H}_{12}\right)$ & $\begin{array}{l}298 \\
298\end{array}$ & $\begin{array}{l}55 \\
40\end{array}$ & $\begin{array}{l}556 \pm 31 \\
394 \pm 31\end{array}$ & $\begin{array}{l}<3 \\
46\end{array}$ & $\begin{array}{l}>500 \\
77\end{array}$ & $\begin{array}{l}0.09 \pm 0.01 \\
0.11 \pm 0.01\end{array}$ & 0.03 (P, 210, Odum et al., 1997) \\
\hline Toluene & 297 & 30 & $231 \pm 61$ & $<3$ & $>500$ & $0.09 \pm 0.02$ & 0.13 (P, 240, Takekawa et al., 2003) \\
\hline$\left(\mathrm{C}_{7} \mathrm{H}_{8}\right)$ & 297 & 30 & $231 \pm 61$ & 51 & 32 & $0.12 \pm 0.03$ & $\begin{array}{l}0.07 \text { (P, 245, Odum et al., 1997) } \\
0.30^{6}(\mathrm{P}, 64, \mathrm{Ng} \text { et al., 2007) }\end{array}$ \\
\hline Ethylbenzene & 297 & 35 & $197 \pm 15$ & $<3$ & $>500$ & $0.33 \pm 0.02$ & 0.09 (P, 230, Odum et al., 1997) \\
\hline$\left(\mathrm{C}_{8} \mathrm{H}_{10}\right)$ & 297 & 32 & $197 \pm 15$ & 130 & 12 & $0.35 \pm 0.02$ & \\
\hline
\end{tabular}

${ }^{1}$ N/M: Not measured

2 This PAM chamber yield is the only yield in this table from ozonolysis in a dark, dry chamber.

3 Our ozonolysis result is compared with ozonolysis run from Presto et al. (2005b).

4 (Oxidation type (O: Ozonolysis, P: Photooxidation by OH radical and ozone), precursor gas amount ( $\Delta \mathrm{HC}$ in ppbv), reference).

5 The high yield 0.39 is obtained from a photooxidation experiment with a neutral seed in the low $\mathrm{NO}_{\mathrm{x}}$ condition (Ng et al., 2007).

6 The high yield 0.30 is obtained from the neutral seeded photooxidation experiment in low $\mathrm{NO}_{\mathrm{x}}$ condition ( $\mathrm{Ng}$ et al., 2007).

producing $20 \mu \mathrm{g} \mathrm{m}^{-3}$ of acidic seed. This increase of yield is qualitatively consistent with the results of Northcross and Jang (2006), who observed a 60 to $70 \%$ increase in SOA yield for acidic seed condition compare to neutral seed condition from the $\alpha$-pinene ozonolysis. Their conditions were quite different from ours; in the PAM chamber, both $\mathrm{OH}$ and $\mathrm{O}_{3}$ oxidized $\alpha$-pinene, while their chamber was dark and ozone was the only oxidant. It has been suggested that yield increases with the presence of the acidic seed aerosol because the acidic surface on the inorganic seed catalyzes the heterogeneous reaction of organic carbonyl species to increase SOA mass (Jang et al., 2002). The qualitative agreement between these two results suggests that the low-volatility products from both $\mathrm{OH}$ and $\mathrm{O}_{3}$ reactions might interact with the acidic seed in similar ways to increase SOA yield.

As little as $15 \mu \mathrm{g} \mathrm{m}^{-3}$ of sulfate aerosol was able to increase the yield of $100 \mathrm{ppbv}$ of $\alpha$-pinene (Fig. 9). It is not possible for us to know the SOA yield in the presence of no acidic seed aerosol, since chambers exposed to $\mathrm{SO}_{2}$ will from then on always generate a few acidic aerosol particles. Therefore, no seed in Fig. 9 actually means that $\mathrm{SO}_{2}$ is not added and the measured sulfate aerosol is less than $5 \mu \mathrm{g} \mathrm{m}^{-3}$ for
10 min average, the precision of TEOM. In the no seed case, the $\alpha$-pinene SOA yield was about $60 \%$ of that observed with added $\mathrm{SO}_{2}$. To within experimental uncertainty, the SOA yield is independent of the acidic aerosol seed mass greater than $15 \mu \mathrm{g} \mathrm{m}^{-3}$. The effect of acidic seed is also independent to within experimental uncertainty of three different $\mathrm{O}_{3}$ values and two different relative humidity levels. These experiments suggest that the acidic seed effect is independent of both the $\mathrm{OH}$ and $\mathrm{O}_{3}$ mixing ratios.

\subsection{SOA yields for various hydrocarbons}

A powerful test of the PAM concept is the comparison of hydrocarbon SOA yields obtained in the PAM chamber with those obtained in large environmental chambers. Similar yields for a number of hydrocarbons under similar conditions provide strong evidence that the aerosol masses obtained from the PAM chamber are the same as those obtained in large environmental chambers. If the large environmental chambers are reasonable simulations of the atmosphere, similar yields also suggest that the PAM measurements represent the potential aerosol mass in the atmosphere. 


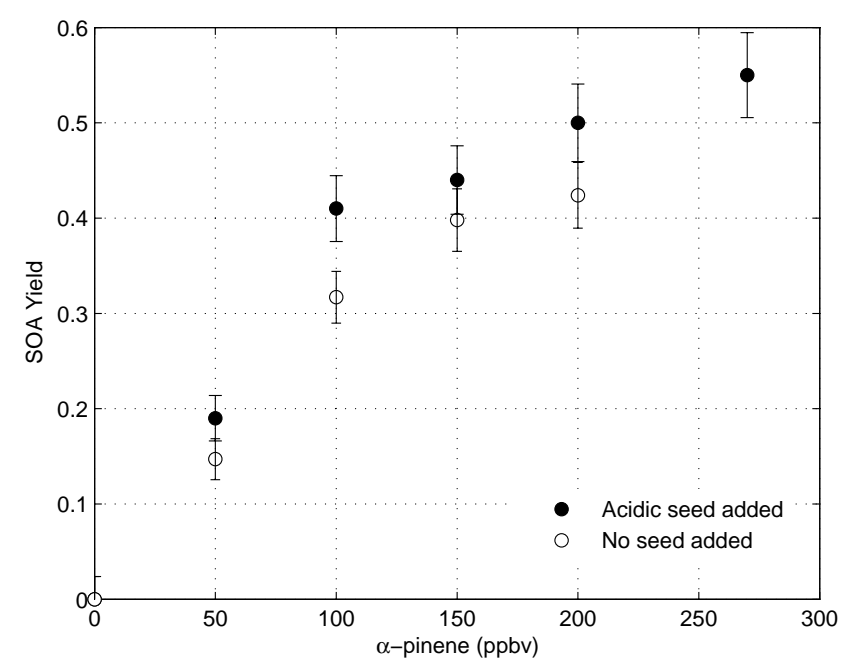

Fig. 8. Acidic seed effect on SOA yield for various $\alpha$-pinene concentrations. Sulfate aerosol, roughly $20 \mu \mathrm{g} \mathrm{m}^{-3}$, from the oxidation of 5 ppb $\mathrm{SO}_{2}$ is used as acidic seed. Error bars show the precision $(1 \sigma)$ for SOA yields.

The SOA yields were measured for three monoterpenes and six anthropogenic hydrocarbons. The three monoterpenes were $\alpha$-pinene, $\beta$-pinene, and $\Delta^{3}$-carene; the six anthropogenic hydrocarbons were cyclohexene, m-xylene, p-xylene, 1,3,5-trimethylbenzne (1,3,5-TMB), toluene, and ethylbenzene. All experiments except some runs for $\alpha$ pinene were performed at a constant temperature ( $297 \pm 1 \mathrm{~K})$, with UV irradiation, in purified air without added acidic seed. $\mathrm{NO}_{\mathrm{x}}$ was added for some experiments to test for a $\mathrm{NO}_{\mathrm{x}}$ effect. In all experiments, $\mathrm{O}_{3}$ was greater than 10 ppmv and $\mathrm{OH}$ was greater than $300 \mathrm{pptv}$. Under these conditions, the hydrocarbons were reacted away; the remaining hydrocarbons were measured to be less than the GC-FID detection limit. The complete list of experiments and the comparisons with previous studies is presented in Table 1. The SOA yields of nine hydrocarbons are compared to those from larger environmental chamber studies that had similar initial precursor gas mixing ratios and chamber conditions.

The PAM yields are similar to the yields from previous studies for $\alpha$-pinene, cyclohexene, m-xylene, p-xylene, $1,3,5-\mathrm{TMB}$, and toluene. If anything, the SOA yields in the PAM chamber are at the high end of the previously reported SOA yields. Two PAM yields $-\beta$-pinene and ethylbenzene are significantly higher than from previous studies; one PAM yield for $\Delta^{3}$-carene, is significantly lower. These differences will be discussed in more detail below.

For all hydrocarbons, we were unable to match exactly the experimental conditions such as temperature, relative humidity, $\mathrm{NO}_{\mathrm{x}}$ mixing ratios, total organic aerosol mass $\left(M_{o}\right)$, and types and amounts of oxidants that were used in the large environmental chamber studies. The values are similar, especially for precursor organic mixing ratios, but not exactly

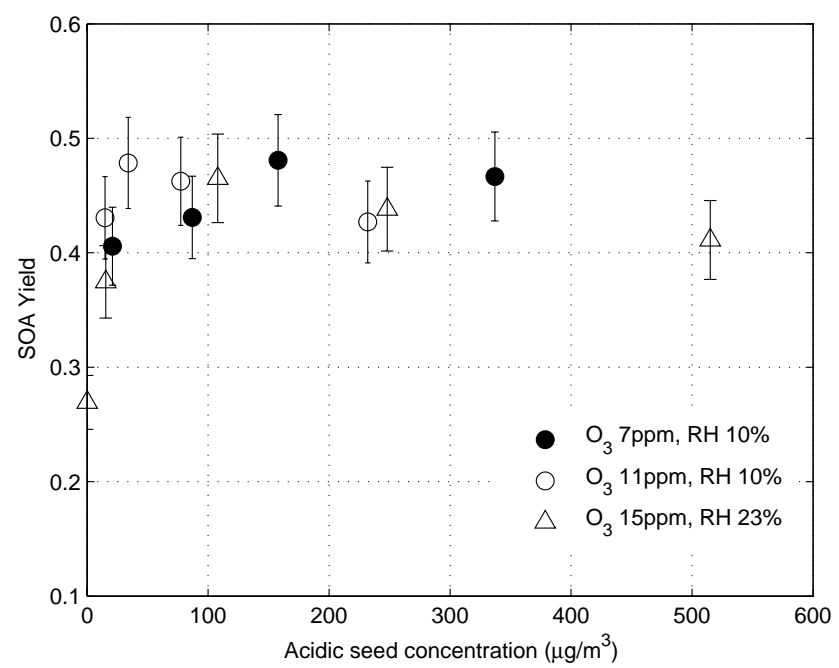

Fig. 9. Acidic seed effect on SOA yield for $100 \mathrm{ppbv}$ of $\alpha$-pinene for photo-oxidation of $100 \mathrm{ppbv}$ of $\alpha$-pinene by different amounts of $\mathrm{O}_{3}$ and $\mathrm{OH} . \mathrm{SO}_{2}$ is added and the resulting sulfate aerosol was used as acidic seed. Note that the SOA yield at zero acidic seed is half all other values. Error bars show the precision $(1 \sigma)$ for SOA yields.

the same. However, despite these differences, the similarity of the PAM and previous yields provides evidence that the rapid oxidation in the PAM chamber simulates SOA formation in the large environmental chambers.

The $\mathrm{NO}_{\mathrm{x}}$ in the PAM chamber is generally much lower than in the previous large environmental chamber studies. Background $\mathrm{NO}_{\mathrm{x}}$ in the PAM chamber was $\sim 3$ ppbv and added $\mathrm{NO}_{\mathrm{x}}$ in some runs was never more than $150 \mathrm{ppbv}$. The ratio of $[\mathrm{VOC}]_{0} /\left[\mathrm{NO}_{\mathrm{x}}\right]_{0}(\mathrm{ppbC} / \mathrm{ppb})$ in the chamber was always higher than 15 for both of background $\mathrm{NO}_{\mathrm{x}}$ condition and added $\mathrm{NO}_{\mathrm{x}}$ conditions. The low $\mathrm{NO}_{\mathrm{x}}$ condition refers to $[\mathrm{VOC}]_{0} /\left[\mathrm{NO}_{\mathrm{x}}\right]_{0}(\mathrm{ppbC} / \mathrm{ppb})>15$; the high $\mathrm{NO}_{\mathrm{x}}$ condition refers to $[\mathrm{VOC}]_{0} /\left[\mathrm{NO}_{\mathrm{x}}\right]_{0}(\mathrm{ppbC} / \mathrm{ppb})<15$ (Presto et al., 2005b; Song et al., 2005). Compared to the previous studies in other chambers, our PAM chamber was operated essentially in the low $\mathrm{NO}_{\mathrm{x}}$ condition for all experiments.

Previous studies in large environmental chambers have examined the differences in SOA yields under high $\mathrm{NO}_{\mathrm{x}}$ and low $\mathrm{NO}_{\mathrm{x}}$ conditions. In most cases, the high $\mathrm{NO}_{\mathrm{x}}$ condition reduced SOA yield for both of biogenic hydrocarbons and anthropogenic hydrocarbons, whereas the SOA yield in low $\mathrm{NO}_{\mathrm{x}}$ condition was the same regardless of the amount of $\mathrm{NO}_{\mathrm{x}}$ (Song et al, 2005; Presto et al., 2005b). For instance, $\alpha$-pinene ozonolysis showed that the SOA yield was constant for $[\mathrm{VOC}]_{0} /\left[\mathrm{NO}_{\mathrm{x}}\right]_{0}(\mathrm{ppbC} / \mathrm{ppb})>15$ and decreased as $[\mathrm{VOC}]_{0} /\left[\mathrm{NO}_{\mathrm{x}}\right]_{0}$ decreased (Presto et al., 2005b). They suggested that as the $[\mathrm{VOC}]_{0} /\left[\mathrm{NO}_{\mathrm{x}}\right]_{0}$ ratio decreases, the volatile product formation increases, thereby reducing aerosol yield. For $[\mathrm{VOC}]_{0} /\left[\mathrm{NO}_{\mathrm{x}}\right]_{0}$ ratios between 3 and 10 , they suggest that a greater amount of nitrate radical $\left(\mathrm{NO}_{3}\right)$ is available 


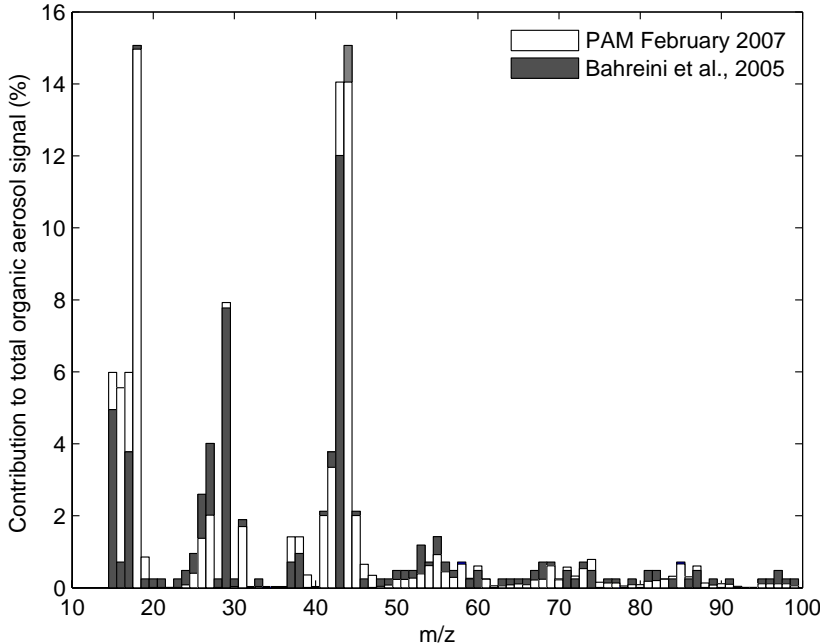

Fig. 10. Contribution to the total organic aerosol signal (\%) for $\mathrm{m} / \mathrm{z}$ from 15 to 100 for photo-oxidation of m-xylene. White is the stable SOA from photo-oxidation of $163 \mathrm{ppbv}$ of m-xylene in the PAM chamber, 21 February 2007; grey is from Bahreini et al. (2005)'s $143 \mathrm{ppbv}$ of m-xylene photo-oxidation. At each mass, the smaller percentage, grey or white, is plotted in front of the larger percentage.

to react with $\alpha$-pinene and that the product of $\alpha$-pinene and $\mathrm{NO}_{3}$ does not contribute aerosol phase.

Our results appear to be inconsistent with recent experiments that used neutral seed particles in the low $\mathrm{NO}_{\mathrm{x}}$ condition (Ng et al., 2007). Ng et al. (2007) observed maximum SOA yield 0.39 and 0.30 for $\mathrm{m}$-xylene and toluene respectively. These values contrast with our studies, in which the stable SOA yield is about 0.10 for both $\mathrm{m}$-xylene and toluene. Part of this difference might be explained by the aerosol seed that was used in the $\mathrm{Ng}$ et al. (2007) experiments but not in ours.

The SOA yield was measured many times for $100 \mathrm{ppbv}$ of $\alpha$-pinene over the course of two years. The standard deviation of all these measurements is large, about $25 \%$ of the mean value of 0.40 . During the two years, many changes were made to the PAM chamber and experimental method as we were learning and the PAM concept was being optimized. Thus, this variability should not be too surprising. None-the-less, the SOA yield for $\alpha$-pinene from the PAM chamber agrees with those from other chambers. The SOA yield for $\beta$-pinene is 0.48 in the PAM chamber. This yield is greater than the SOA yields of 0.27 to 0.32 found in the large environmental chambers. This difference cannot be attributed to a difference in the initial $\beta$-pinene mixing ratios for Lee et al. (2006) or Varutbangkul et al. (2006); the initial $\beta$-pinene was $156 \mathrm{ppbv}$ in the PAM chamber and $170 \mathrm{ppbv}$ for the others. The greater SOA yield from $\beta$-pinene measured in the PAM chamber may be due to its low- $\mathrm{NO}_{\mathrm{x}}$ condition ( $\mathrm{Ng}$ et al., 2006) or to some undetermined difference

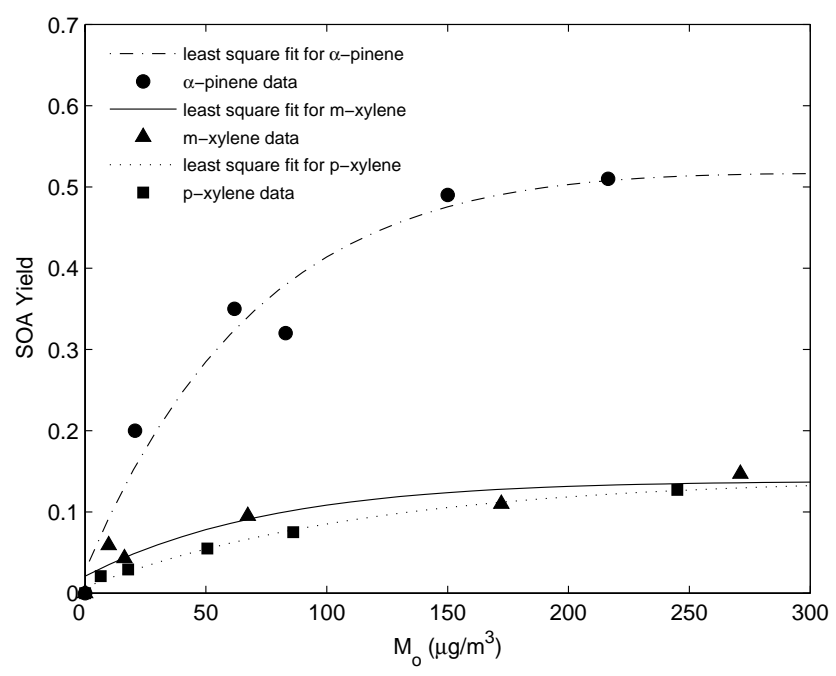

Fig. 11. SOA Yield curve for $\alpha$-pinene, m-xylene, and p-xylene at $20 \% \mathrm{RH}$ and greater than $10 \mathrm{ppmv}$ of ozone and $300 \mathrm{pptv}$ of $\mathrm{OH}$. The least-squares fitted lines are used to determine the yield of individual hydrocarbon in a mixture.

in environmental conditions (Griffin et al., 1999; Lee et al., 2006).

The SOA yields from $\alpha$-pinene and $\beta$-pinene in the PAM chamber appear to be different. However, the SOA yield can be sensitive to the organic aerosol mass, $M_{o}$. When the SOA yield for $156 \mathrm{ppbv}$ of $\beta$-pinene is compared to the SOA yield for $150 \mathrm{ppbv}$ of $\alpha$-pinene (Fig. 11), the two yields are the same, 0.49. This result appears to be consistent with that of Lee et al. (2006).

The SOA yield from ethylbenzene in the PAM chamber, which was 0.34 , is significantly greater than the SOA yield reported in Odum et al. (1997), which was 0.09. The large environmental chamber used in the work of Odum et al. (1997) was operated at a temperature of $\sim 34^{\circ} \mathrm{C}$ (detailed description in Odum et al., 1996). This temperature is $10^{\circ} \mathrm{C}$ higher than the temperature in the PAM chamber. Our study of temperature effects show up to a $40 \%$ decrease in SOA yield for a $7^{\circ} \mathrm{C}$ of temperature increase for $\alpha$-pinene (Fig. 6). Theoretically, SOA yield should decrease at higher temperatures because the partitioning of the semi-volatile organic product shifts toward the gas-phase as the saturation vapor pressure of semi-volatile product increases with temperature (Pankow et al., 2001). Thus, the temperature difference may partially explain the higher SOA yield from ethylbenzene in our PAM chamber experiments, although a series of experiments in the PAM chamber at different temperatures are required to quantify this temperature effect.

The SOA yield of 0.07 from $\Delta^{3}$-carene with $\mathrm{NO}_{\mathrm{x}}$ at chamber background levels was lower than the low end of yields from previous studies, 0.18 (Griffin et al., 1999; Lee et al., 2006). Lee et al. (2006) observed higher SOA yield for ozonolysis than photo-oxidation for $\Delta^{3}$-carene. They 
Table 2. A photooxidation experiment for a hydrocarbon mixture with $\alpha$-pinene, $\mathrm{m}$-xylene and p-xylene.

\begin{tabular}{|c|c|c|c|c|c|c|c|c|c|c|c|}
\hline \multirow{2}{*}{ No } & \multicolumn{3}{|l|}{$\alpha$-pinene } & \multicolumn{3}{|l|}{ m-xylene } & \multicolumn{3}{|l|}{ p-xylene } & \multirow[t]{2}{*}{$\Delta \mathrm{M}_{o}\left(\mu \mathrm{g} / \mathrm{m}^{3}\right)$} & \multirow[t]{2}{*}{$\sum \mathrm{M}_{i}\left(\mu \mathrm{g} / \mathrm{m}^{3}\right)$} \\
\hline & $\Delta \mathrm{HC}(\mathrm{ppb})$ & $\mathrm{Y}$ & $\mathbf{M}_{i}\left(\mu \mathrm{g} / \mathrm{m}^{3}\right)$ & $\Delta \mathrm{HC}(\mathrm{ppb})$ & Y & $\mathbf{M}_{i}\left(\mu \mathrm{g} / \mathrm{m}^{3}\right)$ & $\Delta \mathrm{HC}(\mathrm{ppb})$ & Y & $\mathrm{M}_{i}\left(\mu \mathrm{g} / \mathrm{m}^{3}\right)$ & & \\
\hline 1 & 10 & 0.16 & 8.90 & 13 & 0.05 & 2.79 & 13 & 0.02 & 1.29 & 10.0 & 13.0 \\
\hline 2 & 26 & 0.34 & 48.1 & 33 & 0.09 & 12.3 & 33 & 0.07 & 9.60 & 70 & 69.9 \\
\hline 3 & 33 & 0.44 & 78.4 & 41 & 0.11 & 20.4 & 41 & 0.09 & 16.6 & 117 & 115 \\
\hline 4 & 66 & 0.51 & 165 & 75 & 0.13 & 42.0 & 76 & 0.12 & 38.7 & 200 & 246 \\
\hline
\end{tabular}

observed a low caronaldehyde yield and a high SOA yield from ozonolysis, and a higher caronaldehyde yields and a lower SOA yield from the photo-oxidation. The major difference between ozonolysis and photo-oxidation is the presence of $\mathrm{OH}$ radical. If the $\mathrm{OH}$ or $\mathrm{HO}_{2}$ radical are responsible for the reduction in SOA yield of $\Delta^{3}$-carene by the formation of aldehydes, then the lower SOA yield in the PAM chamber may be due to higher $\mathrm{OH} / \mathrm{O}_{3}$ and $\mathrm{HO}_{2} / \mathrm{O}_{3}$ ratios in the PAM chamber experiments compared to the large environmental chamber experiments of Lee et al. (2006).

\subsection{Comparison of mass spectra from m-xylene}

A critical test of the PAM concept is the comparison of the chemical composition of SOA particles formed in the PAM chamber to the chemical composition of SOA particles formed in large environmental chambers. The percent contribution to the total organic aerosol signal for $\mathrm{m} / \mathrm{z}$ between 15 and 100 is a good indicator of the chemical composition (Jimenez et al., 2003; Bahreini et al., 2005; Alfarra et al., 2006; Canagaratna et al., 2007).

Aerosol mass spectra were measured in the PAM chamber with a Quadruple Aerosol Mass Spectrometer (Q-AMS) from Aerodyne Research Inc. (Jayne et al., 2000). The AMS inlet was inserted into the PAM chamber near the inlet for the TEOM so that total mass and mass spectra were measured simultaneously. Experiments were preformed for three SOA precursor gases $-\alpha$-pinene, $\mathrm{m}$-xylene, and $\mathrm{p}$-xylene at different amounts of precursor gases and oxidants.

To compare the mass spectra taken in the PAM chamber to those taken in large environmental chambers, the amounts of precursor gas should be similar in the two experiments. The PAM chamber experiment with $163 \mathrm{ppbv}$ of $\mathrm{m}$-xylene is quite similar to the amount used for a published mass spectrum of $143 \mathrm{ppbv}$ of m-xylene (Bahreini et al., 2005). The percentage contribution to the total organic mass signal for the two studies is shown in Fig. 10. At each $m / z$, the smaller percentage is plotted in front of the larger. The similarity of the mass spectra indicates that the chemical composition of the particles produced in the PAM chamber is similar to the chemical composition of particles produced in the large environmental chamber.
Differences exist, however, particularly in the ratio of $\mathrm{m} / \mathrm{z}$ 43 , which represents less oxidized organics, to $m / z 44$, which represents more oxidized organics (Zhang et al., 2005; Alfarra et al., 2006). The ratio from the PAM chamber is about 1.0, while the ratio from Bahreini et al. (2005) is 0.8. This difference should not be surprising. The degree of oxidation depends on the total exposure to oxidants and on the initial precursor gas amount, which affects to total SOA mass. The smaller the precursor gas amount, the more oxidized the SOA particle will be for a given exposure to oxidants. The lower m-xylene amount in the Bahreini et al. (2005) experiment means that the SOA particles should be more aged and have a lower $m / z, 43$ to $m / z, 44$ ratio than the SOA particles in the PAM chamber, as is observed. Taking the differences in precursor gas amount into account explains most of the differences in the $\mathrm{m} / \mathrm{z}, 43$ to $\mathrm{m} / \mathrm{z}, 44$ ratio that were observed.

\subsection{SOA yields from a hydrocarbon mixture of $\alpha$-pinene, $\mathrm{m}$-xylene, and p-xylene}

A recent study suggests that the large number of cocondensing semi-volatile gases results in the formation of aerosol mass much greater than the expected sum of the yields of individual hydrocarbons (Volkamer et al., 2006). If this enhancement is due to an increase in SOA yields in any common mixture of atmospheric hydrocarbons, then it would be possible to test this enhancement with experiments in the PAM chamber. For this experiment, the SOA yield of a hydrocarbon mixture of $\alpha$-pinene, $\mathrm{m}$-xylene, and $\mathrm{p}$-xylene in a 1.00:1.25:1.25 ratio was measured and compared with the sum of the individual SOA yields.

To calculate the sum of the yields of the individual hydrocarbons, the yield of each individual hydrocarbon was measured as a function of total organic aerosol mass, $M_{o}$, for the individual hydrocarbon:

$\Delta H C_{i} \times Y_{i}\left(M_{o}\right)=M_{i}$
$\sum M_{i}=M_{o}$

We assume that the yield of any individual hydrocarbon depends on the total organic aerosol mass, $M_{o}$, regardless of the origin of organic aerosol. Thus, to get the estimated SOA mass of individual hydrocarbon species $\left(M_{i}\right)$, the SOA yield value of each hydrocarbon corresponding to the total SOA 

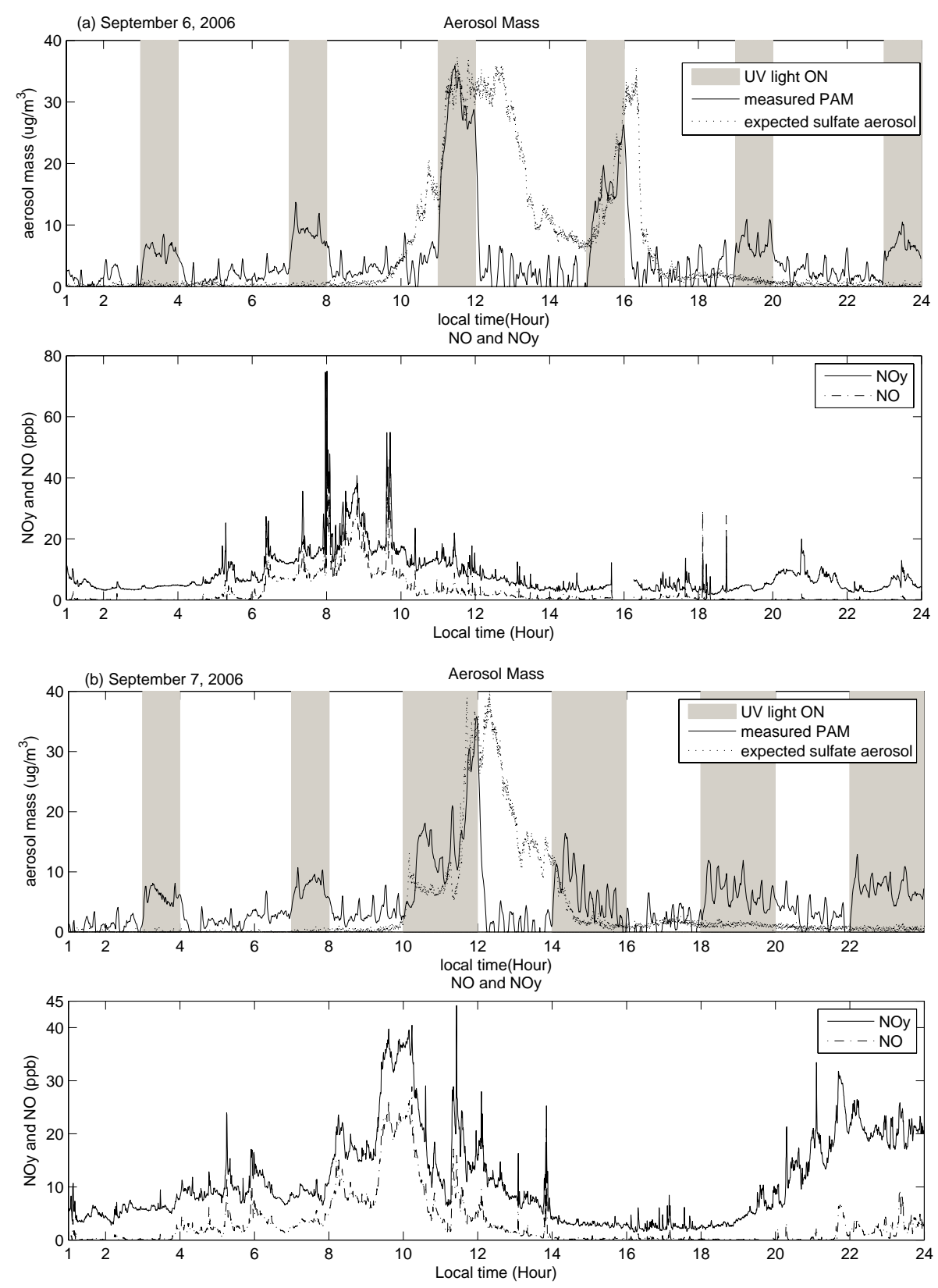

Fig. 12. PAM measurements in ambient aerosol-free air on 6 September 2006 (a) and on 7 September 2006 (b). For the two days the relative humidity was $38 \pm 3 \%$ and the temperature was $31 \pm 1^{\circ} \mathrm{C}$ in the chamber. The UV-irradiated chamber (gray bar) had 4 ppmv of ozone and $\sim 400$ pptv of $\mathrm{OH}$. Calculated sulfate aerosol (dashed line) was obtained with the measured $\mathrm{SO}_{2}$ multiplied by the $\mathrm{SO}_{2}$ consumption ratio 0.5 and the calculated conversion factor $4.67 \mu \mathrm{g} \mathrm{m}^{-3}\left(\mathrm{ppbv} \mathrm{SO}_{2}\right)^{-1}$. Measured PAM (solid line) was the measured aerosol mass by TEOM. $\mathrm{NO}_{\mathrm{y}}, \mathrm{NO}$ and $\mathrm{SO}_{2}$ were measured by NATIVE.

mass in the mixture, $Y_{i}\left(M_{o}\right)$, was obtained from the individual yield curve in the Fig. 11, and multiplied to reacted hydrocarbon concentration $\left(\triangle H C_{i}\right)$. The calculated mass, $M_{i}$, for all three hydrocarbons were then summed up to give the expected SOA mass, $\sum M_{i}$, which could then be compared with $M_{o}$, the total SOA mass measured in the mixture (Eq. 8).

Four different hydrocarbon mixing ratios were used, although the mixture of the three hydrocarbons was constant
(Table 2). In all four experiments, $M_{o}$ was similar to $\sum M_{i}$ within a factor of 1.3 or better. Thus, this mixture does not exhibit an enhancement in the SOA over what is expected from the individual hydrocarbon.

This conclusion is the same as reported by Odum et al. (1997). They observed good agreement of $M_{o}$ and $\sum M_{i}$ for anthropogenic mixture containing toluene, m-xylene, m-ethyltoluene, n-propylbenzene, 1,2,4-trimethylbenzene. 
Their experiments were performed in large environmental chamber using sunlight. Typical sunlight can produce up to 100 ppbv of $\mathrm{O}_{3}, 0.2 \mathrm{pptv}$ of $\mathrm{OH}$, and 20 pptv of $\mathrm{HO}_{2}$ daytime in urban area (Ren et al., 2006). Our PAM chamber is operated in highly oxidizing condition with more than $10 \mathrm{ppmv}$ of $\mathrm{O}_{3}, 300$ pptv of $\mathrm{OH}$, and 3 ppbv of $\mathrm{HO}_{2}$. While the oxidant mixing ratios were 100 times larger than in either the large environmental chamber or the atmosphere, the ratios of the oxidants were similar. Thus, the result obtained in the PAM chamber likely applies to the atmosphere.

This agreement also supports the argument of Seinfeld and Pankow (2003) that the SOA yield is only dependent on the organic mass concentration, and organic aerosols are not interacting each other in a mixture. However, the greater SOA yield observed when acidic inorganic seed was present in the smog chamber indicates that the organics are interacting with the inorganic acid to increase the SOA yield (Jang et al., 2002). More mixtures that include both inorganic and organic precursor gases will need to be tested in the PAM chamber to examine this synergistic effect on SOA yield.

This agreement is also inconsistent with Robinson et al. (2007). They tested diluted diesel exhaust and observed higher SOA mass than expected from a model that used known SOA yields from VOCs. They suggest that many IVOC (Intermediate-Volatility Organic Carbons) were in the diesel exhaust, resulting in the higher SOA mass than expected. It may be that some simple mixtures, such as the ones used by Odum et al. (1997), and us, contain fewer and less IVOCs.

The comparison of $\sum M_{i}$ to $M_{o}$ suggests that simultaneous measurements of PAM and all known volatile organic compounds can be used to test for unmeasured VOCs that can be oxidized to form SOA in the atmosphere during field studies. $\sum M_{i}$ might be less than $M_{o}$ for four possible reasons: unmeasured SOA-precursor VOCs; errors in the measurements of SOA-precursor VOCs; SOA yield values that are either incorrect or not applicable to the atmospheric environment; and synergetic enhancement of SOA by co-condensing gases, such as the SOA yield increase on acidic seed aerosol. Examining these issues will require the simultaneous deployment of the PAM chamber, aerosol mass and chemical measurements, and measurement of all known precursor inorganic and organic atmospheric constituents in a field study.

\subsection{Results from a preliminary field study}

A first field test of PAM was conducted in September 2006. The PAM instrument was installed in the Nittany Atmospheric Trailer and Integrated Validation Experiment (NATIVE) trailer at the Pennsylvania State University campus in the University Park, Pennsylvania. In the NATIVE trailer are measurements of $\mathrm{SO}_{2}, \mathrm{NO}, \mathrm{NO}_{\mathrm{y}}, \mathrm{CO}, \mathrm{O}_{3}, \mathrm{UV}$ radiation, relative humidity, temperature, pressure, and wind speed and direction. The PAM chamber was placed inside of the trailer and the inlet was located $1.8 \mathrm{~m}$ above the trailer roof. The gas sampling inlet was at the same height as the PAM chamber sampling inlet.

It is possible to sample either ambient air containing aerosol particles or air run through a HEPA aerosol particle filter. By turning the UV light in the chamber on and then off periodically for both ambient air and aerosol-free air, the aerosol mass, potential aerosol mass, and sum of the two can all be measured by the PAM chamber and the TEOM instrument. However, for this preliminary study, only aerosol free air was sampled. The chamber was operated with a flow rate through the chamber of $10 \mathrm{Lmin}^{1}$ and only one UV light, which produced 4 ppmv of ozone and about 400 pptv of OH, with an ambient relative humidity of $38 \%$. These conditions are more than sufficient to oxidize all of the hydrocarbons in the laboratory experiments, and were in fact chosen because they do optimize the yields for all hydrocarbons tested. But experiments show that only $50 \%$ of the $\mathrm{SO}_{2}$ was oxidized.

Examples of the PAM measurements come from two days, 6 September 2006 and 7 September 2006 (Fig. 12). The formation of secondary aerosol is shown in the shaded periods when the chamber was irradiated with UV. Increases in measured aerosol mass occur every time the chamber is irradiated with UV light. Typically the increase was 5 to $10 \mu \mathrm{g} \mathrm{m}^{-3}$. This potential aerosol mass appears to come from sources other than either $\mathrm{SO}_{2}$ or $\mathrm{NO}_{\mathrm{y}}$. Unfortunately, for this preliminary study, no hydrocarbon measurements were made and the origins of the potential aerosol mass could not be ascertained.

In some cases, a $\mathrm{SO}_{2}$ plume was sampled. The measured $\mathrm{SO}_{2}$ mixing ratio can be converted into an expected sulfate aerosol mass by accounting for the partial $50 \%$ conversion of $\mathrm{SO}_{2}$ to sulfate and using the calculated conversion ratio of $4.67 \mu \mathrm{g} \mathrm{m}^{-3}$ (ppbv $\left.\mathrm{SO}_{2}\right)^{-1}$, which is appropriate for the $30 \%$ relative humidity at the TEOM mass transducer. For 6 September 2006, the measured and calculated potential aerosol mass agreed to well within experimental uncertainties, indicating that in these air samples, the potential aerosol mass consisted only of $\mathrm{SO}_{2}$. However, on 7 September 2006, the potential aerosol mass measurement was 5 to $10 \mu \mathrm{g} \mathrm{m}^{-3}$ greater than expected from $\mathrm{SO}_{2}$, indicating that the air masses containing $\mathrm{SO}_{2}$ on 7 September 2006 also contained other aerosol-forming gases. A comparison between the potential aerosol mass and $\mathrm{NO}_{\mathrm{y}}$ suggests that the additional potential aerosol mass was not due to $\mathrm{NO}_{\mathrm{y}}$.

These results from this preliminary field test show the feasibility of the PAM concept for ambient air. The PAM chamber conditions, while sufficient for this preliminary study, were not optimized. The many experiments that have been conducted since September 2006 provide insight into the PAM chamber operating conditions and protocols that will give much better and much more information that was obtained then. 


\section{Conclusions}

We have introduced the concept of Potential Aerosol Mass (PAM) and have performed experiments with inorganic and organic precursor gases to test its feasibility. These experiments provide strong evidence that PAM is a viable concept. PAM measurements can be made with a small, simple, flowthrough chamber with a few minutes of exposure time in a highly oxidizing environment. The PAM chamber has two advantages over larger environmental chambers: negligible wall effects and the ability to complete the experiments in minutes, not hours.

We have demonstrated that the sulfate yield agrees to within $6 \%$ of theory. This agreement shows that the conversion of $\mathrm{SO}_{2}$ to sulfate can be complete even in a chamber with only a few minutes of residence time. It also shows that the wall loss of sulfate aerosol particles in the PAM chamber is negligible.

The behavior of the SOA yields as a function of variables, such as temperature, relative humidity, oxidant concentration, presence of $\mathrm{NO}_{\mathrm{x}}$, precursor gas composition and amount, and the presence of acidic seed aerosol were generally comparable to the results found in large environmental chambers. Differences remain, possibly due to our inability to closely match the conditions in the large environmental chambers. However, the SOA yields disagree for different environmental chambers and even for different years in the same chamber. Some of these differences are understood; some are not. Thus, the PAM SOA yields are validated by their general consistency with the SOA yields in the large bulk-type environmental chambers. At the same time, these new results complement those found in the large environmental chambers.

A novel aspect of the PAM chamber experiments is the direct measurements of the oxidants $\mathrm{O}_{3}, \mathrm{OH}$, and $\mathrm{HO}_{2}$ in the chamber. These direct measurements enabled the quantification of these oxidants as a function of UV light and relative humidity. As a result, the ratios can be varied by at least a factor of 10 in the range of oxidant ratios that are observed in the low- $\mathrm{NO}_{\mathrm{x}}$ troposphere. This variability enables a careful examination of SOA formation and aging in both chambers and the atmosphere.

The focus of this paper is on the definition of the PAM concept and the demonstration that SOA yields from PAM chamber experiments are comparable to those found in large environmental chambers. In a subsequent paper will be discussed measurements of the evolution of the SOA chemical composition and particle size distributions in the PAM chamber. Preliminary analyses indicate that particle chemical composition and size distributions obtained in the PAM chamber experiments are comparable to those observed in large environmental chambers.

The goal of definitively defining Potential Aerosol Mass has not yet been achieved; only the feasibility of the PAM concept has been demonstrated. The PAM chamber still needs to be optimized and the operating conditions still need to be better understood. Studies will need to be conducted over a wider range of atmospheric conditions and chemical composition to create a working definition of PAM.

The PAM chamber has the potential to be a powerful tool for experimental studies in the laboratory and large environmental chambers. The PAM chamber can be coupled to a wide range of gas and particle measurement tools. It provides an extreme, well-characterized oxidation environment - essentially a low-temperature flame - that enables tests of SOA formation and aging in large chambers and the atmosphere.

PAM measurements can be an inexpensive indicator of the presence of aerosol precursor gases in monitoring networks and sites where measurements of speciated aerosol precursor gases are not feasible on a routine basis, where resources for environmental monitoring instruments are scarce, or where particulate pollution problems are fierce. Also, the simultaneous deployment of the PAM chamber, aerosol mass and chemical measurements, and measurement of all known precursor inorganic and organic atmospheric constituents in a field study can be used to test any unmeasured VOCs that can be oxidized to form SOA. Furthermore, the in-situ measurement of PAM in monitoring networks can be used to track the transport of precursor gases in air masses.

Acknowledgements. This research is supported by NSF grant ATM-0518783. We thank R. Lesher for support with the electronics and data collection system, Z. Chen for operation of the Gas Chromatograph, and B. Taubman for helping with the PAM measurements in the NATIVE trailer. We also thank J. Scollins and R. Storer for their help in the initial phases of the PAM development and experiments.

Edited by: T. Kirchstetter

\section{References}

Alfarra, M. R., Paulsen, D., Gysel, M., Garforth, A. A., Dommen, J., Prévôt, A. S. H., Worsnop, D. R., Baltensperger, U., and Coe, H.: A mass spectrometric study of secondary organic aerosols formed from the photooxidation of anthropogenic and biogenic precursors in a reaction chamber, Atmos. Chem. Phys., 6, 52795293, 2006, http://www.atmos-chem-phys.net/6/5279/2006/.

Bahreini, R., Keywood, M. D., Ng, N. L., Varutbangkul, V., Gao, S., Flagan, R. C., Seinfeld, J. H., Worsnop, D. R., and Jimenez, J. L.: Measurements of secondary organic aerosol from oxidation of cycloalkenes, terpenes, and $m$-xylene using an aerodyne aerosol mass spectrometer, Environ. Sci. Technol., 39, 5674-5688, 2005. Canagaratna, M. R., Jayne, J. T., Jimenez, J. L., Allan, J. D., Alfarra, M. R., Zhang, Q., Onasch, T. B., Drewnick, R., Coe, H., Middlebrook, A., Delia, A., Williams, L. R., Trimborn, A. M., Northway, M. J., DeCarlo, P. F., Kolb, C. E., Davidovits, P., and Worsnop, D. R.: Chemical and microphysical characterization of 
ambient aerosols with the Aerodyne Aerosol Mass Spectrometer, Mass Spectrom. Rev., 26, 185-222, 2007.

Cocker III, D. R., Flagan, R. C., and Seinfeld, J. H.,: State-of-theArt chamber facility for studying atmospheric aerosol chemistry, Environ. Sci. Technol., 35, 2594-2601, 2001.

Demerjian, K. L.: A review of the national monitoring networks in North America, Atmos. Environ., 34, 1861-1884, 2000.

Drewnick, F., Schwab, J. J., Jayne, J. T., Canagaratna, M. R., Worsnop, D. R., and Demerjian, K. L.,: Measurement of ambient aerosol composition during the PMTACS-NY 2001 using an Aerosol Mass Spectrometer. Part I: Mass concentrations, Aerosol. Sci. Tech., 38, 92-103, 2004b.

Faloona, I. C., Tan, D., Lesher, R. L., Hazen, N. L., Frame, C. L., Simpas, J. B., Harder, H., Martinez, M., Di Carlo, P., Ren, X., and Brune, W. H.: A laser-induced fluorescence instrument for detecting tropospheric $\mathrm{OH}$ and $\mathrm{HO}_{2}$ : Characteristics and calibration, J. Atmos. Chem., 139-167, 2004.

Gao, S., Keywood, M., Varutbangkul, V., Bahreini, R., Flagan, R. C., and Seinfeld, J. H.: Low-molecular-weight and oligomeric components in secondary organic aerosol from the ozonolysis of cycloalkenes and alpha-pinene, J. Phys. Chem., A108, $10147-$ $10164,2004$.

Griffin, R. J., Cocker III, D. R., Flagan, R. C., and Seinfeld, J. H.: Organic aerosol formation of oxidation of biogenic hydrocarbons, J. Geophys. Res., 104, 3555-3567, 1999.

Huebert, B., Bertram, T., Kline, J., Howell, S., Eatough, D., and Blomquist, D.: Measurements of organic and elemental carbon in Asian outflow during ACE-Asia from the NSF/NCAR C130, J. Geophy. Res., 109, D19S11, doi:10.1029/2004JD004700, 2004.

Intergovernmental Panel on Climate Change (IPCC), Working Group I, Climate change: The scientific basis, Cambridge Univ. Press, New York, 2001.

Jaecker-Voirol, A. and Mirabel, P.: Nucleation rate in a binary mixture of sulfuric acid and water vapor, J. Phys. Chem., 92, 3518$3521,1988$.

Jaecker-Voirol, A., Ponche, J. L., and Mirabel, P.: Vapor pressures in the ternary system water-nitric acid-sulfuric-acid at low temperatures, J. Geophys. Res., 95, 11 857-11 863, 1990.

Jang, M., Czoschke, N. M., Lee, S., and Kamens, R. M.: Heterogeneous atmospheric aerosol production by acid-catalyzed particlephase reactions, Science, 298, 814-817, 2002.

Jayne, J. T., Leard, D. C., Zhang, X., Davidovits, P., Smith, K. A., Kolb, C. E., and Worsnop, D. R.: Development of and Aerosol Mass Spectrometer for size and composition analysis of submicron particles, Aerosol. Sci. Tech., 33, 49-70, 2000.

Jimenez, J. L., Jayne, J. T., Shi, Q., Kolb, C. E., Worsnop, D. R., Yourshaw, I., Seinfeld, J. H., Flagan, R. C., Zhang, X., Smith, K. A., Morris, J. W., and Davidovitx, P.: Ambient aerosol sampling using the Aerodyne Aerosol Mass Spectrometer, J. Geophys. Res., 108, doi:10.1029/2001JD001213, 2003.

Jonsson, A. M., Hallquist, M., and Ljungstrom, E.: Impact of humidity on the ozone initiated oxidation of Limonene, $\Delta^{3}$-carene, and $\alpha$-pinene, Environ. Sci. Technol., 40, 188-194, 2006.

Kamens, R., Jang, M., Chien, C., and Leach, K.: Aerosol formation from the reaction of $\alpha$-pinene and ozone using a gas-phase kinetics-aerosol partitioning model, Environ. Sci. Technol., 33, 1430-1438, 1999.

Kamens, R. M. and Jaoui, M.: Modeling aerosol formation from $\alpha$-pinene $+\mathrm{NO}_{\mathrm{x}}$ in the presence of natural sunlight using gasphase kinetics and gas-particle partitioning theory, Environ. Sci. Technol., 35, 1394-1405, 2001.

Keywood, M. D., Varutbangkul, V., Bahreini, R., Flagan, C., and Seinfeld, J. H.: Secondary organic aerosol formation from the ozonolysis of cycloalkenes and related compounds, Environ. Sci. Technol., 38, 4157-4164, 2004.

Krewski, D., Burnett, R. T., Goldberg, M. S., Hoover, K., Siemiatycki, J., Jerrett, M., Abrahamowicz, M, and White, W. H.: Reanalysis of the Harvard six-cites study and the American Cancer Society study of particulate air pollution and Mortality, Part II: Sensitivity analysis. Cambridge, Massachusetts, Health Effects Institute, A Special Report of the Institute's Particle Epidemiology Reanalysis Project, 129-130, 2000.

Lall, R., Kendall, M., Ito, K., and Thurston, G. D.: Estimation of historical annual $\mathrm{PM}_{2.5}$ exposures for health effects assessment, Atmos. Environ., 38, 5217-5226, 2004.

Lanz, V. A., Alfarra, M. R., Baltensperger, U., Buchmann, B., Hueglin, C., and Prévôt, A. S. H.: Source apportionment of submicron organic aerosols at an urban site by factor analytical modeling of aerosol mass spectra, Atmos. Chem. Phys., 7, 15031522, 2007, http://www.atmos-chem-phys.net/7/1503/2007/.

Lee, A., Goldstein, A. H., Kroll, J. H., Ng, N. L., Varutbangkul, V., Flagan, R. C., and Seinfeld, J. H.: Gas-phase products and secondary aerosol yields from the photooxidation of 16 different terpenes, J. Geophys. Res., 111, D17305, doi:10.1029/2006JD007050, 2006.

Long, R. W., Eatough, N. L., Eatough, D. J., Meyer, M. B., and Wilson, W. E.: Continuous determination of fine particulate matter mass in the Salt Lake City Environmental Monitoring project: a comparison of real-time and conventional TEOM monitor results, J. Air. Waste. Manage., 55(12), 1839-1846, 2005.

Martín-Reviejo, M. and Wirtz, K.: Is benzene a precursor for secondary organic aerosol?, Environ. Sci. Technol., 39, 1045-1054, 2005.

Murphy, D. M., Thomson, D. S., and Mahoney, M. J.: In situ measurements of organics, meteoritic material, mercury, and other elements in aerosols at 5 to 19 Kilometers, Science, 282, 16641669, 1998.

The National Institute of Standards and Technology (NIST) chemical kinetics Standard Reference Database 17, Version 7.0 (Web Version), Release 1.4, (http://www.nist.gov/srd/chemkin.htm), 2000.

Ng., N. G., Kroll, J. H., Keywood, M. D., Bahreini, R., Varutbangkul, V., Flagan, R. C., and Seinfeld, J. H.: Contribution of first-versus second-generation products to secondary organic aerosols formed in the oxidation of biogenic hydrocarbons, Environ. Sci. Technol., 40, 2283-2297, 2006.

Ng., N. L., Kroll, J. H., Chan, A. W. H., Chhabra, P. S., Flagan, R. C., and Seinfeld, J. H.: Secondary organic aerosol formation from m-xylene, toluene, and benzene, Atmos. Chem. Phys. Discuss., 7, 4085-4126, 2007,

http://www.atmos-chem-phys-discuss.net/7/4085/2007/.

Northcross, A. L. and Jang, M.: Heterogeneous SOA yield from ozonolysis of monoterpenes in the presence of inorganic acid, Atmos. Environ., 41, 1483-1493, 2006.

Odum, J., Hoffmann, T., Bowman, F., Collins, D., Flagan, R., and Seinfeld, J. H.: Gas/particle partitioning and secondary organic 
aerosol yields, Environ. Sci. Technol., 30, 2580-2585, 1996.

Odum, J. R., Jungkamp, T. P. W., Griffin, R. J., Flagan, R. C., and Seinfeld, J. H.: The atmospheric aerosol-forming potential of whole gasoline vapor, Science, 276, 96-99, 1997.

Pankow, J. F., Seinfeld, J. F., Asher, W. E., and Erdakos, G. B.: Modeling the formation of Secondary organic aerosol. 1. Application of theoretical principles to measurements obtained in the $\alpha$-pinene/, $\beta$-pinene/, sabinene/, $\Delta^{3}$-carene/, and cyclohexene/ozone systems, Environ. Sci. Technol., 35, 1164-1172, 2001.

Presto, A. A., Huff Hartz, K. E., and Donahue, N. M.: Secondary organic aerosol production from terpene ozonolysis. 1. Effect of UV radiation, Environ. Sci. Technol., 39, 7036-7045, 2005a.

Presto, A. A., Huff Hartz K. E., and Donahue, N. M.: Secondary organic aerosol production from terpene ozonolysis. 2. Effect of $\mathrm{NO}_{\mathrm{x}}$ concentration, Environ. Sci. Technol., 39, 7046-7054, $2005 b$.

Ren, X., Brune, W. H., Oliger, A., Metcalf, A. R., Simpas, J. B., Shirley, T., Schwab, J. J., Bai, C., Roychowdhury, U., Li, Y., Cai, C., Demerjian, K., He, Y., Zhou, X., Gao, H., and Hou, J.: $\mathrm{OH}, \mathrm{HO}_{2}$, and $\mathrm{OH}$ reactivity during the PMTACS-NY Whiteface Mountain 2002 campaign: Observations and model comparison, J. Geophys. Res., 111, D10S03, doi:10.1029/2005JD006126, 2006.

Robinson, A. L., Donahue, N. M., Shrivastava, M. K., Weitkamp, E. A., Sage, A. M., Grieshop, A. P., Lane, T. E., Pierce, J. R., and Pandis, S. N.: Rethinking organic aerosols: Semivolatile emissions and photochemical aging, Science, 315, 1259, doi:10.1126/science.1133061, 2007.

Root, M. J.: Determining the major oxidants in an environmental chamber, M. S. Thesis, The Pennsylvania State University, 2007.

Salcedo, D., Onasch, T. B., Dzepina, K., Canagaratna, M. R., Zhang, Q., Huffman, J. A., DeCarlo, P. F., Jayne, J. T., Mortimer, P., Worsnop, D. R., Kolb, C. E., Johnson, K. S., Zuberi, B., Marr, L. C., Volkamer, R., Molina, L. T., Molina, M. J., Cardenas, B., Bernabé, R. M., Márquez, C., Gaffney, J. S., Marley, N. A., Laskin, A., Shutthanandan, V., Xie, Y., Brune, W., Lesher, R., Shirley, T., and Jimenez, J. L.: Characterization of ambient aerosols in Mexico City during the MCMA-2003 campaign with Aerosol Mass Spectrometry: results from the CENICA Supersite, Atmos. Chem. Phys., 6, 925-946, 2006, http://www.atmos-chem-phys.net/6/925/2006/.

Schwab, J. J., Hogrefe, O., Demerjian, K. L., and Ambs, J. L.: Laboratory characterization of modified tapered element oscillating microbalance samplers, J. Air. Waste. Manage., 54(10), 12541263, 2004.

Schwab, J. J., Felton, H. D., Rattigan, O. V., and Demerjian, K. L.: New York State urban and rural measurements of continuous PM2.5 mass by FDMS, TEOM, and BAM, J. Air. Waste. Manage., 56(4), 372-383, 2006.
Seinfeld, J. H. and Pandis, S. N.: Atmospheric chemistry and physics, John Wiley and Sons, Inc., New York, 997-1000, 11391143, 1998.

Seinfeld, J. H., Erdakos, G. B., Asher, W. E., and Pankow, J. F.: Modeling the formation of secondary organic aerosol (SOA). 2. The predicted effect of relative humidity on aerosol formation in the $\alpha$-pinene, $\beta$-pinene, sabinene, $\Delta^{3}$-carene, and cyclohexeneozone systems, Environ. Sci. Technol., 35, 1806-1817, 2001.

Seinfeld, J. H. and Pankow, J. F.: Organic atmospheric particulate material, Annu. Rev. Phys. Chem., 54, 121-140, 2003.

Song, C., Na, K., and Cocker III, D. R.: Impact of the hydrocarbon to $\mathrm{NO}_{\mathrm{x}}$ ratio on secondary organic aerosol formation, Environ. Sci. Technol., 39, 3143-3149, 2005.

Takekawa, H., Minoura, H., and Yamazaki, S.: Temperature dependence of secondary organic aerosol formation by photo-oxidation of hydrocarbons, Atmos. Environ., 37, 3413-3424, 2003.

Teom 1400A monitor, Technical note 4: Low temperature operation of the TEOM series 1400-PM 10 moitor, http://www.rpco.com/ products/ambprod/amb1400/index.htm, 1992.

Varutbangkul, V., Brechtel, F. J., Bahreini, R., Ng, N. L., Keywood, M. D., Kroll, J. H., Flagan, R. C., Seinfeld, J. H., Lee, A., and Goldstein, A. H.: Hygroscopicity of secondary organic aerosols formed by oxidation of cycloalkenes, monoterpenes, sesquiterpenes, and related compounds, Atmos. Chem. Phys., 6, 23672388, 2006, http://www.atmos-chem-phys.net/6/2367/2006/.

Vehkamaki, H., Kulmala, M., Napari, I., Lehtinen, K. E. J., Timmreck, C., Noppel, M., and Laaksonen A.: An improved parameterization for sulfuric acid-water nucleation rates for tropospheric and stratospheric conditions, J. Geophys. Res., 107, doi:10.1029/2002JD002184, 2002.

Volkamer, R., Jimenz, J. L., Martini, F. S., Dzepina, K., Zhang, Q., Salcedo, D., Molina, L. T., Worsnop, D. R., and Molina, M. J.: Secondary organic aerosol formation from anthropogenic air pollution: Rapid and higher than expected, J. Geophys. Res., 33, L17811, doi: 10.1029/2006GL026899, 2006.

Wilson, W. E., Grover, B. D., Long, R. W., Eatough, N. L., and Eatough, D. J.: The measurement of fine particulate semivolatile material in urban aerosols, J. Air. Waste. Manage., 56(4), 384 397, 2006.

Zhang, Q., Alfarra, M. R., Worsnop, D. R., Allan, J. D., Coe, H., Canagaratna, M. R., and Jimenez, J. L.: Deconvolution and quantification of hydrocarbon-like and oxygenated organic aerosols based on Aerosol Mass Spectrometer, Environ. Sci. Technol., 39, 4938-4952, 2005. 